University of Zurich

Department of Economics

Working Paper Series

ISSN 1664-7041 (print)

ISSN 1664-705X (online)

Working Paper No. 258

\title{
Hunting Unicorns? Experimental Evidence on Predatory Pricing Policies
}

Aaron Edlin, Catherine Roux, Armin Schmutzler and Christian Thöni

June 2017 


\title{
Hunting Unicorns? Experimental Evidence on Predatory Pricing Policies
}

\author{
Aaron Edlin ${ }^{\S}$ Catherine Roux ${ }^{\llbracket}$ Armin Schmutzler॥ Christian Thöni**
}

May 19, 2017

\begin{abstract}
We study the anticompetitive effects of predatory pricing and the efficacy of three policy responses. In a series of experiments where an incumbent and a potential entrant interact, we compare prices, market structures and welfare. Under a laissez-faire regime, the threat of post-entry price cuts discourages entry, and allows incumbents to charge monopoly prices. Current U.S. policy (Brooke Group) does not help. A policy suggested by Baumol (1979) lowers post-exit prices, while Edlin's (2002) proposal reduces pre-entry prices and encourages entry. While both policies show outcomes after entry that are less competitive than under Laissez-Faire, they nevertheless increase consumer welfare.
\end{abstract}

JEL Classification: D21, K21, L12, L13, C91

Keywords: Predatory Pricing; Entry Deterrence; Firm Strategy; Antitrust Law; Experiment

\footnotetext{
${ }^{\ddagger}$ We thank Luís Cabral, Thomas De Haan, Kai-Uwe Kühn, Chloé Le Coq, Igor Letina, John Mayo and Giancarlo Spagnolo as well as various seminar audiences for helpful comments and discussions. Financial support from the Economic Policy profile area of the University of St. Gallen is gratefully acknowledged.

$\S$ University of California, Berkeley. E-mail: aedlin@berkeley.edu

ฯUniversity of Basel. E-mail: catherine.roux@unibas.ch

"University of Zurich. E-mail: armin.schmutzler@econ.uzh.ch

${ }^{* *}$ University of Lausanne. E-mail: christian.thoeni@unil.ch
} 


\section{Introduction}

Incumbent monopolies often respond aggressively to entry. Names for this behavior vary, depending upon context or upon whether the name caller thinks it is desirable. The aggressive response could be called "vigorous competition" or "predatory pricing" when there is a single product, or it might be called a "bundled discount" or a "price-squeeze" when there are multiple products. Regardless of the context, an important question is whether entrants should ever be protected from such exclusionary pricing if they cannot survive on their own and if so how? Typically, in a predatory pricing case, aggressive response to entry is tested by comparing some measure of the monopoly's price to cost, and entrants are only protected from below-cost pricing. Increasingly, litigants, legal scholars, and courts extend below-cost pricing tests to multiproduct pricing conduct and some argue that nonprice aggression like exclusive dealing should be handled the same way (Eilat et al., 2016). ${ }^{1}$

We study the question of when aggressive responses to entry should be regulated in the specific context of the one-product predatory pricing debate, but we believe our analysis has wider implications. In particular, we ask when, if ever, unrestricted price cutting by a monopoly is undesirable either because it drives entrants from the market or because its prospect discourages entry. Our experimental approach suggests that there may be consumer or competition gains from regulating price cutting, at least when a monopoly incumbent has cost advantages.

Previous literature has focused mainly on below-cost predatory pricing. Skeptical commentators have variously compared this pricing behavior to unicorns (Baker, 1994, p.586), dragons (Easterbrook, 1981, p.264), and basketball players scoring sixty four points in a game (Elzinga and Mills, 2001, p.2479). They argue that price cutting is generally good for consumers and they contend that it is bad only in fairy tales told by theorists or in extremely rare circumstances in practice. $^{2}$ This argument would support a laissez-faire policy to predatory pricing.

\footnotetext{
${ }^{1}$ For a discussion on how the approaches to predatory pricing and to margin squeeze are related see, for example, OECD, Margin Squeeze DAF/COMP(2009)36 and Gaudin and Mantzari (2016). See also FTC and DOJ, Workshop Transcript on Conditional Pricing Practices: Economic Analysis \& Policy Implications (June 23, 2014) on the predatory pricing standard for conditional pricing practices.

${ }^{2}$ In the wake of this view, a comprehensive theoretical literature developed to rationalize
} 
It has been used by the U.S. Supreme Court to justify a test for legality that bans only price cuts which leave prices below marginal or average variable cost (Brooke Group, 1993). ${ }^{3}$

We think the focus on below-cost pricing may be misguided. Incumbent monopolies often have cost or other advantages, which may be the reason why they are monopolists. Such advantages are difficult to offset by potential entrants in the short term. In such settings, above-cost price cuts are the real threat (see e.g. Farrell and Saloner (1986)): it is entirely credible that an incumbent monopoly will react to entry by pricing below an entrant's cost but above its own cost. Such pricing, though indistinguishable from static equilibrium play, has undesirable effects: like below-cost predatory pricing, it will drive the entrant from the market. Because of these exclusionary effects, it has been called "above-cost predatory pricing". Our aim is not to determine what motivates the firm's aggressive pricing, i.e., to pin down predatory intent, but rather to study the exclusionary effects of such pricing behavior. In particular, we ask whether price drops after entry discourage entry, or eliminate the threat of entry in a way that hurts consumers or overall welfare, and whether policies can improve the situation. We call such exclusionary pricing "above-cost predatory pricing" if it is above the monopoly's cost, and "below-cost predatory pricing" if it is below the monopoly's cost. ${ }^{4}$

A typical view of the tradeoff in predatory pricing policy, be it above or below cost, is that condemning these low prices sacrifices a beneficial price war (a bird in hand) in the speculative hope of promoting lower prices in the future (a bird in the bush). The beneficial price war is, however, equally speculative and will

predatory pricing by means of reputation-building (Kreps and Wilson, 1982), signaling models (Milgrom and Roberts, 1982; Scharfstein, 1984; Fudenberg and Tirole, 1986; Saloner, 1987) and financial constraints (Bolton and Scharfstein, 1990). These theories are mostly based on information asymmetries and center on the idea that the incumbent has an incentive to influence the entrant's beliefs about future profits. We study a simpler setting without any information asymmetries. Theories of predation that do not depend on information asymmetries include Harrington (1986); Cabral and Riordan (1994, 1997); Motta and Fumagalli (2013).

${ }^{3}$ Brooke Group Ltd. v. Brown 6 Williamson Tobacco Corp. 509 U.S. 209 (1993).

${ }^{4}$ Edlin (2002, 2012), Salop (2005, 2006), Popofsky (2006) and Hovenkamp (2005) all discuss above-cost exclusionary conduct. In a famous predatory pricing case, Barry Wright, Judge Breyer (as a district court judge before he joined the Supreme Court) acknowledged that abovecost price cuts could be undesirable but worried that problematic price cutting could not be distinguished from desirable limit pricing that discouraged entry but provided persistent low prices to consumers. 
only happen if there is entry. And lack of entry is the big problem in a monopoly market. If a high-cost rival fears predatory pricing, it will not challenge a lowcost incumbent even if the latter charges high prices. The consequence can be persistent high pricing without entry. To remedy this, Edlin (2002) proposes that an incumbent should not be allowed to lower its prices substantially to avoid being undercut by an entrant. The idea is to encourage low pricing by the incumbent prior to entry and to encourage entry if the incumbent charges high prices. This policy is thus dynamic, focusing on price patterns, in contrast to Brooke Group which focuses on price level.

Baumol (1979) likewise proposed a dynamic policy to combat predatory pricing. The Baumol policy would prevent an incumbent from raising prices after having fought off an entrant with price cuts. This policy might have better properties than Edlin's conditional upon entry because then price competition is not restricted, but it does not appear to offer entrants as much protection and could in theory still allow persistent high prices if it does not manage to facilitate entry.

This paper serves two purposes. First, we provide an experimental test for the existence of above-cost predatory pricing. Second, we compare the effectiveness of different policy rules (Brooke Group, Baumol and Edlin) in mitigating its effects.

To date, there is mainly anecdotal evidence for predatory pricing. For instance, in the American Airlines case in the U.S., several entrants were driven from the Dallas-Fort Worth market by American. American priced high before entry and after exit. The entrants brought significantly lower prices, but only for short periods before they were driven from the market. The Department of Justice introduced evidence showing that American priced low to drive entrants out, but could not win their case under the prevailing policy (Brooke Group rule) because American did not price below its variable cost. Although there is some systematic empirical work to identify predatory pricing (e.g., Lerner (1995); Scott Morton (1997); Podolny and Scott Morton (1999); Genesove and Mullin (2006)), this work does not analyze policy effects.

To go beyond anecdotal evidence, we use a laboratory approach. Existing experiments focus on below-cost pricing trying to settle the debate about whether it exists, is credible, and induces exit. The seminal paper in this literature is Isaac and Smith (1985), which defines predatory pricing as pricing below marginal cost 
(at p. 330), and searches for it in vain, thereby supporting the unicorn view. ${ }^{5}$ Overall, the evidence on below-cost pricing in the laboratory is mixed: while Harrison (1988) reports numerous cases of below-cost pricing in an experiment with multiple markets, Goeree and Gomez (1998), replicating Harrison's study, find virtually no evidence of below-cost pricing. However, in a modified design with entry prior to pricing decisions and a simpler demand schedule, a reliable pattern of below-cost predation emerges (Goeree and Gomez, 1998; Capra et al., 2000). Likewise, Chiaravutthi (2007) finds substantial evidence of below-cost predatory pricing in markets with network externalities. ${ }^{6}$

We study predatory pricing in the lab because of a central problem with any empirical approach to the subject: such pricing may deter entry without ever being observed. Would-be entrants, willing to price much lower than a monopolist, do not enter for fear of being wiped out in a subsequent price war (Ezrachi and Gilo, 2009, 2010). Identifying such a problem in the field is challenging. If we see "insufficient entry," when can we attribute it to predatory pricing?" Without policy variation, we cannot reliably know what would happen under alternative policies. Would there be more entry? Would prices be lower? In the lab, we can exogenously vary policy, while leaving everything else fixed. We can compare a laissez-faire environment with one where price cuts are restricted. Behavioral differences between the two settings can thus unambiguously be attributed to the possibility of predatory pricing. Moreover, the experimental approach allows us to identify the causal effects of different policies in a particularly clean fashion, as it is straightforward to implement ceteris paribus policy variations in the lab. ${ }^{8}$

We study a setting with perfect information and without financial constraints. There is an incumbent monopoly with low costs, but a rival might be tempted

\footnotetext{
${ }^{5}$ Isaac and Smith (1985) hypothesize that as there is no predatory pricing, antitrust intervention will ironically limit competition. They study the Baumol policy and find that Baumol's policy leads to cooperatively shared monopoly. They neither study Edlin nor Brooke Group.

${ }^{6}$ Jung et al. (1994) report instances of predatory behavior in an experimental chain store signaling game where they allow reputations to develop. Their results are somewhat difficult to put in our context as there is no information of firms' prices and quantities.

${ }^{7} \mathrm{An}$ interesting approach to the related problem of not being able to empirically identify the threat of entry separately from actual entry is Goolsbee and Syverson (2008). They show that incumbents respond to entry announcements in the passenger airline industry.

${ }^{8}$ Another reason for taking predatory pricing to the laboratory is the difficulty to apply costbased tests in practice (Normann and Ricciuti, 2009; Gomez et al., 2008).
} 
to enter because the incumbent's monopoly price exceeds the rival's cost. An unregulated monopolist can thus drive the rival from the market while still earning positive profits. Our basic question is whether entry results and how this depends upon the policy environment.

We consider dynamic Bertrand-style price competition over four market periods, allowing for four policy treatments: 1. "Laissez-faire," which has no regulation; 2. "Brooke Group," which bans below-cost pricing; 3. "Baumol," which makes post-entry price cuts permanent; and 4. "Edlin," which bans certain postentry price cuts. These policies affect entry and exit as well as pre- and post-entry pricing; thereby they influence consumer and total welfare.

Under policies 1-3, any equilibrium involves monopoly pricing for four periods with no entry: the policies make no connection between pre-entry prices and future prices, so that the firms will charge monopoly prices prior to entry. Moreover, the rival will not enter because the incumbent will respond with price reductions, driving the entrant from the market and making entry unprofitable.

Under Edlin, there is likewise no entry, but to ensure this, the monopoly must price low prior to entry, because it is not free to cut prices after entry. ${ }^{9}$ In theory, Edlin's proposal thus leads to higher consumer surplus and welfare because it makes the market contestable. Thus, the high-cost entrant can play an efficiencyenhancing role without entering the market.

Our experiment shows that in Laissez-faire there tends to be monopoly pricing prior to entry, and there is often no entry (consistent with a fear of post-entry predation). When entry does arise, it usually is a mistake because nothing stops the incumbent from driving the entrant from the market. As a result, the entrant ends up losing the sunk cost of entry. While incumbents typically drive entrants from the market with prices below the entrant's break-even level, the incumbent does not price below its own cost. Therefore, the Brooke Group policy which bans below-cost pricing amounts to hunting unicorns and should have no effect in our setting. This turns out to be true. As expected, behavior under Brooke Group is indistinguishable from Laissez-faire and equally bad for consumers.

Edlin's policy has two consumer benefits. It lowers the monopoly's pre-entry price and it increases the frequency of entry in instances where the monopoly sets

\footnotetext{
${ }^{9} \mathrm{An}$ exception is the final period, when it charges the monopoly price due to end-game effects.
} 
a price that is not exclusionary. The first is a prediction of theory and the second is a prediction of what happens off the equilibrium path. When the incumbent monopolist prices high prior to entry under Edlin, entry is typically profitable because the monopolist cannot immediately respond with low prices. However, as expected, duopoly prices are usually higher than in the other treatments.

Baumol's policy suffers from monopoly pricing prior to entry just as Brooke Group and Laissez-faire do. On the other hand, Baumol has the lowest prices after exit because price cuts are permanent. Baumol leads to more entry than Brooke Group and Laissez-faire, though less than Edlin.

The overall effect of the policies on consumer surplus differs considerably from the effect on total welfare. For sufficiently experienced players, Edlin and Baumol both deliver higher consumer surplus than the remaining policies, with Edlin the highest. Contrary to the theoretical prediction, however, total welfare is lower in Edlin than in the other three cases. This result is the downside of the entrypromoting effect of Edlin's policy, which implies duplication of fixed costs.

The remainder of this paper is organized as follows. Section 2 introduces the model and the experimental design, and it derives theoretical predictions. Section 3 presents the results. Section 4 concludes.

\section{Theory and Experimental Design}

\subsection{The Game}

In this subsection, we explain the general framework and the four game variantsLaissez-faire, Brooke Group, Baumol, and Edlin - used in the experiment.

Two firms, a low-cost incumbent $L$ and a high-cost potential entrant $H$ (henceforth, "the rival"), can produce a homogeneous good and participate in a fourperiod game. In period 1, only the incumbent is present in the market. In periods 2-4, each firm decides whether to participate in the market or to stay out. A firm that chooses to stay out earns a payoff of 50 per period from an outside option. To participate in the market, a firm has to pay 250 per period. Thus, including the opportunity cost from the foregone outside option, the fixed costs are 300 per period. Once a firm decides to exit, it cannot re-enter in subsequent periods. 
We opted for per-period costs, rather than only one-shot set-up costs, because having recurring fixed costs such as rent is typically realistic and is required to make exit meaningful and different from zero production. We chose not to include set-up costs in addition to per-period costs, because this would have increased the complexity of the experiment for subjects substantially. For simplicity, we also excluded a re-entry option.

In each period, the market demand is given by

$$
D(p)=80-p
$$

If only one of the firms $i=L, H$ is active in the market in a given period, its demand function coincides with the market demand. Facing this demand, it chooses its price as a monopolist. Suppose now both firms are active in the market in a given period. They simultaneously and independently choose a price $p_{i}$ for the production of the homogeneous good. Their action sets are integers in an interval $[\underline{p}, \bar{p}]$ with treatment-specific boundaries. Consumers buy at the lowest price. Hence, each firm faces the following demand:

$$
D_{i}\left(p_{i}, p_{j}\right)=\left\{\begin{array}{cl}
80-p_{i} & \text { if } p_{i}<p_{j} \\
\frac{1}{2}\left(80-p_{i}\right) & \text { if } p_{i}=p_{j} \\
0 & \text { if } p_{i}>p_{j}
\end{array}\right.
$$

A firm is considered dominant in a given period $t$ if it produced and served the entire market in the prior period $t-1 .^{10}$ Firm $i$ 's duopoly payoff in a given period is

$$
\pi_{i}=\left(p_{i}-c_{i}\right) D_{i}\left(p_{i}, p_{j}\right)-250
$$

where $c_{i}$ is the marginal cost. The incumbent has a technological advantage over the rival and thus produces the good at a lower marginal cost. Marginal costs are $c_{L}=20$ for the incumbent and $c_{H}=30$ for the rival.

The games differ with respect to the interval $[\underline{p}, \bar{p}]$ in which the dominant firm can choose its price. A firm which is not dominant can always choose its price in

\footnotetext{
${ }^{10}$ This includes both the cases that the firm was a monopolist and the case that it undercut the competitor in duopoly. Moreover, it applies to the incumbent as well as to the rival.
} 
the entire interval $[0,80]$. In our baseline game, Laissez-faire, the dominant firm can choose, on an equal footing with the entrant, its price in the interval $[0,80]$.

In the Brooke Group game, a dominant firm in a duopoly in period $t$ cannot choose a price below its own marginal cost in that period, that is, it is restricted to choosing $p_{i}^{t} \in\left[c_{i}, 80\right]$.

In the Baumol game, a restriction in pricing in period $t$ applies only after exit of the competitor of the dominant firm. In this case, the firm is not allowed to choose a price above its price in $t-1$ in period $t$ and all subsequent periods. Hence, $p_{i}^{t+k} \in\left[0, p_{i}^{t-1}\right]$ for $k=0,1 \ldots, 4-t$. If the other firm has not left the market in $t$, the dominant firm can choose its price in the entire interval $[0,80]$.

Finally, in the Edlin game, in period $t$ the dominant firm faces a price floor such that it cannot choose a price below $80 \%$ of its price in $t-1$, that is, $p_{i}^{t} \in$ $\left[0.8 \cdot p_{i}^{t-1}, 80\right]$. This restriction applies only if the market in $t$ is a duopoly.

To sum up, we implement an experimental game that is as simple as possible, but still sufficiently rich to study the strategic incentives created by the policies. Thus, we made the following design decisions: (a) no re-entry possibility; (b) a finite time-horizon; (c) asymmetric marginal costs; (d) a specific choice of the Edlin parameter (0.8). Our choice of the allowable price reduction $(20 \%$, as suggested by Edlin (2002)) was guided by the consideration that it should give incentives for the incumbent to reduce pre-entry prices to deter entry as well as incentives to an entrant to meaningfully undercut the prices of a high price incumbent. ${ }^{11}$

\subsection{Predictions}

We now describe the subgame-perfect equilibria of the four games underlying our experimental treatments. For simplicity, we carry out the analysis for continuous price sets. Moreover, we define the total fixed cost $F$ so that it includes the opportunity cost of 50 from the foregone outside option. Hence, $F=300$. We first introduce some self-explanatory terminology.

1. The break-even price $p_{\theta}^{B}$ for $\theta \in\{L, H\}$ is given by $\left(p_{\theta}^{B}-c_{\theta}\right) D\left(p_{\theta}^{B}\right)=F$.

2. The entry-deterring price $p^{*}$ of $L$ in the Edlin game is defined by $0.8 p^{*}=p_{H}^{B}$.

\footnotetext{
${ }^{11}$ It will be clear from the analysis below that, with a sufficiently large allowable reduction, the incumbent could keep the price at the monopoly level and still fight off the entrant.
} 
It is important to note that the break-even price is calculated by setting the economic profit equal to zero rather than the payoffs (that do not account for the opportunity cost of the foregone outside option).

Figure 1 gives an overview of the relevant prices and marginal costs. Most
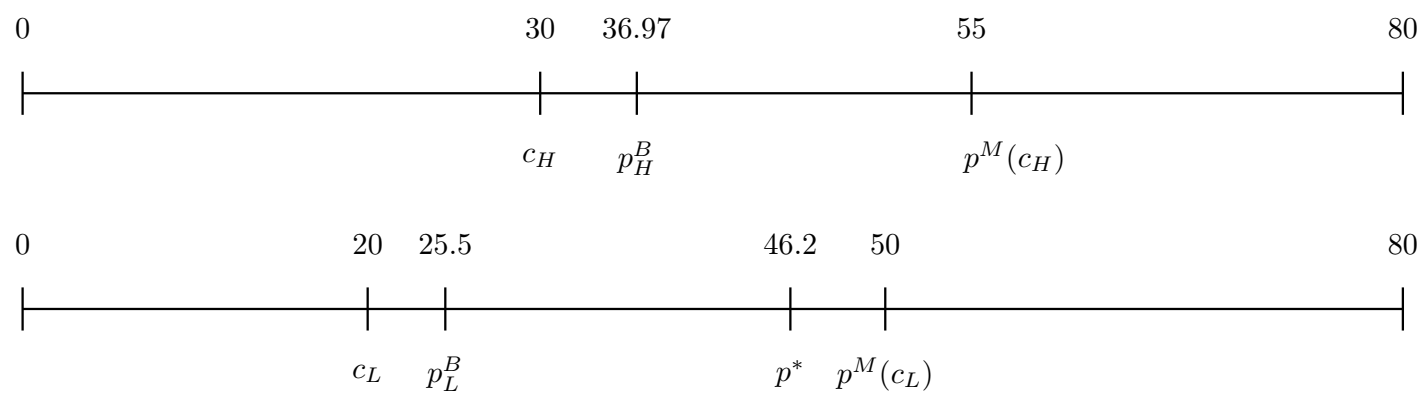

Figure 1: Overview of the prices (for firm $H$ and firm $L$ )

aspects of the ordering depicted in this figure hold for all conceivable parameterizations, not just for those chosen for the experiment. However, two comparisons are specific to our parameterization: first, the break-even price $p_{L}^{B}$ of firm $L$ is below the marginal cost $c_{H}$ of firm $H$. Thus, our assumptions on demand, marginal and fixed costs reflect a situation with a substantial cost advantage of the incumbent. ${ }^{12}$ Second, the entry-deterring price $p^{*}$ is below the monopoly price of the low-cost firm $\left(p^{M}\left(c_{L}\right)\right)$. This reflects the choice of a sufficiently rigid Edlin restriction as discussed above.

We formulate the results in a non-technical way. We confine ourselves to describing the equilibrium outcome and the most important features of the equilibrium strategies. Apart from the proofs, the online appendix contains precise formal statements of equilibrium strategies and tie-breaking rules.

\subsubsection{Laissez-Faire and Brooke Group Games}

We treat the Laissez-faire and Brooke Group games together, as the analysis is essentially the same.

Proposition 1. The Laissez-faire and Brooke Group games both have a subgameperfect equilibrium (SPE) in pure strategies. The SPE outcome is that there is no

\footnotetext{
${ }^{12}$ Without this assumption, further equilibria would emerge.
} 
entry and the incumbent charges its monopoly price. The equilibrium strategies in each period are such that pricing in any period is independent of previous prices. Moreover, the rival will exit from duopoly immediately after any off-equilibrium entry. Finally, any SPE has these properties.

The intuition is straightforward. In both games, both firms are essentially free to set arbitrary prices. ${ }^{13}$ Prices therefore do not affect future behavior. Thus, in each period, firms set prices that are optimal in the short term. In particular, in any duopoly situation, the incumbent undercuts the entrant in equilibrium. Anticipating this, the rival will not enter.

It is intuitively clear that Proposition 1 does not depend on the details of our parameterization: the only thing that matters is that prices today do not affect prices and entry behavior tomorrow.

\subsubsection{Baumol Game}

The Baumol game is much more complex. After entry, the incumbent knows that, if it undercuts the rival, its duopoly price is an upper bound for future prices if the rival exits. Intuitively, this reduces the incumbent's incentives to fight against the rival with low prices. It must weigh the short-term benefits from undercutting against the long-term benefits from being allowed to charge the monopoly profit. As we show in more detail in the appendix, in duopoly subgames the resolution of this trade-off leads to the occurrence of multiple equilibria where prices do not necessary equal the rival's marginal cost. However, none of these equilibria yields prices that are high enough for the entrant to break even. As a result, there is no entry in any equilibrium. The following result summarizes the equilibrium. It relies on tie-breaking rules that are stated in more detail in the appendix.

Proposition 2. The Baumol game has an SPE without entry in which the incumbent sets its monopoly price in all periods. In this SPE, in any subgame with a duopoly, the asymmetric Bertrand equilibrium where both firms charge the high cost $c_{H}$ is played in periods 2-4. In addition, there are other SPE yielding the

\footnotetext{
${ }^{13}$ In the Brooke Group game, prices below own costs are not allowed, but the incumbent does not rationally choose such prices anyway.
} 
same outcome, with prices in period 2 above $c_{H}$, but below the rival's break-even point. All SPE are of this type.

The equilibrium outcome is thus the same as in the Laissez-faire and Brooke Group games. ${ }^{14}$ The difference exclusively concerns off-equilibrium behavior. Thus, while Proposition 2 does not predict entry, it suggests that exclusionary pricing might be less likely to emerge under Baumol's policy.

\subsubsection{Edlin Game}

The equilibrium prediction of the Edlin game and the off-equilibrium behavior differ from the two previous cases.

Proposition 3. The Edlin game has an SPE without entry, in which the incumbent sets the entry-deterring price $p^{*}$ except in period 4 where it charges the monopoly price. The equilibrium strategies involve hit-and-run entry in the offequilibrium path where the incumbent prices above $p^{*}$ : the entrant prices just below the incumbent's Edlin restriction and exits in the next period. Any equilibrium has these properties.

Intuitively, the crucial aspect of the Edlin game is that, after sufficiently high incumbent prices, the entrant can earn positive net profits for one period by undercutting the Edlin restriction. Anticipating this, the incumbent faces two options. First, it can choose the monopoly price, which will attract entry. Second, it can choose an entry-deterring price, thereby avoiding entry, but earning lower preentry profits. Given our parameterization, the latter option is more attractive. Thus, though the SPE does not involve entry, the Edlin rule has a desirable effect on prices.

Note, however, that there also is a sense in which the Edlin rule seems to be more conducive to entry than the alternatives: after high prices of the incumbent, the rival will rationally enter because it is protected from competition. This differs from the previous games where entry does not occur in any subgame equilibrium.

\footnotetext{
${ }^{14} \mathrm{An}$ open issue here is to which extent the equilibrium structure depends on parameters. For instance, with a longer interaction, the incumbent may be more reluctant to fight after entry, which could, in turn, lead to greater entry incentives.
} 


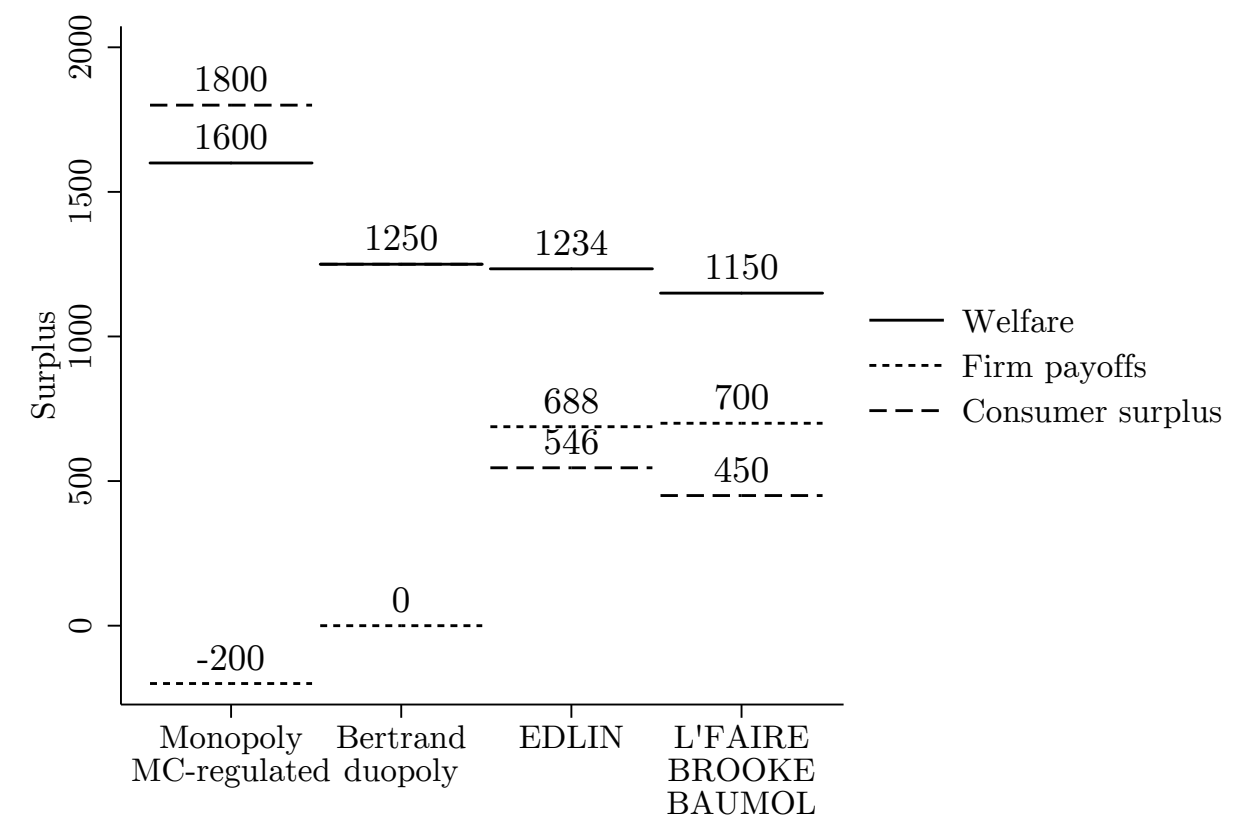

Figure 2: Welfare benchmarks of the four policies, a low-cost monopoly with marginal cost regulation, and Bertrand competition.

\subsubsection{Welfare}

Figure 2 shows the welfare results in the equilibria of our four games. For comparison, we plot the welfare results for a low-cost monopoly under marginal cost regulation. In this case, the incumbent makes a loss of 250. Because the rival does not enter the market it earns the payoff from the outside option (50), which brings the sum of the firms' payoffs to -200 . We also plot the welfare results for the Bertrand duopoly case, in which the low-cost firm serves the market at a price equal to the high-cost firm's marginal cost. In this case, the former's payoff of 250 is exactly offset by the loss of the latter, such that the sum equals zero and overall welfare is equal to consumer surplus.

At the other extreme, we consider a completely unregulated low-cost monopoly, resulting in low consumer surplus and total welfare, but high firms' payoffs. This corresponds to the outcome of the Laissez-faire, Brooke Group and Baumol games. 
The SPE of the Edlin game predicts no entry and entry-deterring prices in periods $1-3$. In the discrete version of the game, this means setting a price of 46, which results in firms' profits of 684 (including the 50 of the rival), and a consumer surplus of 578. The numbers shown in Figure 2 take into account that this outcome is only predicted for periods $1-3$, while in period 4 the outcome of the Edlin game is identical to the other three policies. The results show that -if the first-best is not available - there are several alternatives that might increase welfare: among the equilibria of our four games the Edlin game results in a higher level of consumer surplus and total welfare than Laissez-faire, Brooke Group and Baumol, because pre-entry prices are lower and there is no adverse effect on market structure. Bertrand competition is desirable for different reasons: even if it comes with a duplication of the fixed costs, it guarantees low duopoly prices.

\subsection{Experimental Design and Procedures}

We apply a between-subjects design, so that each subject is assigned to one of the treatments L'FAIRE, BROOKE, BAUMOL, or EDLIN. Each treatment consists of seven rounds of the respective four-period game outlined above. In all treatments, we use a stranger matching protocol such that, at the beginning of each round, groups of two subjects are randomly drawn from the subjects in a matching group. In each group and in each round, the roles (incumbent or rival) are randomly reassigned within the groups. When a new round starts and the subjects are newly matched, neither subject knows anything about the decisions of the other firm in prior rounds. Within a given round, the roles and the firms remain the same. At the end of each period, subjects are informed about the market price, the output sold, and the payoffs realized by each of the firms in their group.

The sessions were run in the WiSo experimental research laboratory of the University of Hamburg in July 2015 and were programmed in z-Tree (Bock et al., 2014; Fischbacher, 2007). Subjects were randomly allocated to computer terminals in the laboratory so that they could not infer with whom they would interact. Throughout the experiment, communication was not allowed. We provided written instructions which informed the subjects of all the features of the markets (see Appendix B). Similar to other studies on experimental oligopolies, we used an 
economic framing (see, e.g., Huck et al. (2004)), where we explain the strategic situation in terms of firms, prices, and quantities. Prior to the start of the treatment, subjects had to answer control questions. When answering the control questions and when choosing their actions during the game, subjects had access to a payoff calculator allowing them to calculate the payoff of hypothetical combinations of their actions and the actions chosen by their competitors.

We calculated the payoffs in the experiment in an experimental currency unit called points. At the beginning of the session, subjects were endowed with 1500 points to cover potential losses. The payments to the subjects consisted of a $€ 5$ show-up fee plus the sum of the payoffs over the course of the experiment. The sessions lasted for about 90 minutes, and the average earnings were $€ 16.80$. We conducted ten sessions - two sessions per treatment for L'FAIRE and BROOKE and three sessions per treatment for BAUMOL and EDLIN - with a total of 228 participants. The subjects were undergraduate students from the University of Hamburg.

\section{Results}

We first show that in L'FAIRE above-cost predatory pricing occurs frequently. As a result, many participants do not enter, and those who do often exit. After that, we investigate the potential of the three policies to improve the situation. Throughout our analysis, we distinguish between three market structures: (i) PreEntry, the phase from period one until entry which captures all situations in which the incumbent needs to worry about future entry; ${ }^{15}$ (ii) Duopoly, after the rival has entered the market and the two firms compete, namely, the phase in which we may observe exclusionary behavior; and (iii) PostExit, after one of the two firmstypically the rival - has left the market and, thus, no entry threat exists. ${ }^{16}$ Finally, we discuss the dynamics across the seven rounds of the game.

\footnotetext{
${ }^{15}$ More precisely, we define PreEntry as consisting of all periods in which the rival did not yet enter, except period four. We exclude the final period, because the incumbent no longer can have any concerns about future market entry.

${ }^{16}$ The three market structures are typically encountered in this specific order. In very few cases, we observe that the incumbent exits and the rival enters in the same period or later. In this case, the group moves directly from PreEntry to PostExit.
} 


\subsection{Predatory Pricing Under Laissez-Faire}

In this section, we first show that above-cost predatory pricing is prevalent under Laissez-faire. We define pricing as predatory (or exclusionary) if it prevents a rival from breaking even; such pricing provides rivals with the incentive to exit a market or not to enter in the first place. By this definition, when the incumbent charges 37 or below, it is predatory pricing because the entrant cannot help but lose money by being in the market. ${ }^{17}$ The definition thus encompasses both below-cost and above-cost predatory pricing.

Prior to entry (in PreEntry), the incumbent is a monopoly and prices as such. The average observed price is 49.6 , with 83 percent of the cases at exactly the monopoly price of $50 .{ }^{18}$ Entry lowers the average incumbent's price substantially to 34.9 , which is in the exclusionary range of 37 and below. ${ }^{19}$

Figure 3 shows the frequency of incumbents' duopoly prices for different price ranges. No incumbent prices below its own marginal cost of 20, so that there is no below-cost predatory pricing, and such pricing is a unicorn in our game. However, most incumbents (75 percent) respond to entry with above-cost predatory pricing: 26 percent of the prices are in the category above the incumbent's marginal cost and below the rival's marginal cost, while around half of the observations (49 percent) are above the rival's marginal cost and below the rival's break-even point. As a consequence, entrants usually make a loss. The average profit is -235 per period, and entrants only earn a positive profit in 13.4 percent of the cases when they are in competition with an incumbent. Presumably as a reaction, most entrants leave the market: among the 93 cases where rivals join the duopoly market in periods two or three, 57 (61.3 percent) leave the market at some point, so that the incumbent is again in a monopoly.

\footnotetext{
${ }^{17}$ In the discrete version of the game, the rival cannot break even if the incumbent sets 37 . It cannot profitably undercut the incumbent as $36<p_{H}^{B}$; and the variable duopoly profits obtained when both firms charge 37 do not suffice to cover fixed costs.

${ }^{18}$ The frequent choice of the price 50 might partly be explained by the fact that 50 is a prominent number. However, in the cases when the rival becomes a monopolist, we also observe the monopoly price (55) frequently (70 percent), indicating that most subjects are able to find payoff maximizing solutions.

${ }^{19}$ The decrease is highly significant ( $p=.008$, exact Wilcoxon signed-rank test). This and all subsequent non-parametric tests are based on independent matching group averages.
} 


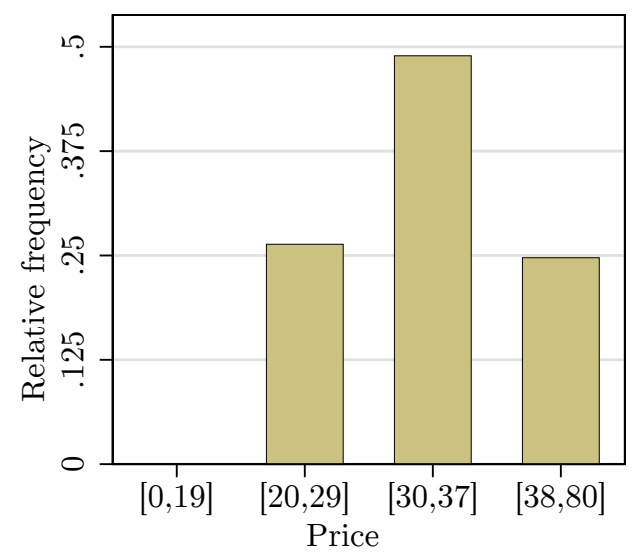

Figure 3: Incumbent prices in Duopoly of L'FAIRE.

Aside from the fact that entrants do not remain in the market, the most important effect of exclusionary pricing is that rivals do not dare to contest the incumbent in the first place. In one third of all rounds, rivals do not enter. Over the course of the seven rounds, there is a clear trend towards less entry. While in the first round 95.8 percent of the rivals enter the market, the percentage drops to 41.7 percent in the final round. Thus, by the time the rivals anticipate the incumbents' likely reaction, most do not enter.

After the incumbent has successfully pushed the entrant out of the market, the game is in the PostExit structure. The incumbents switch back to monopoly pricing with an average of $50.7 .^{20}$

Result 1. In L'FAIRE, incumbents generally engage in above-cost predatory pricing. They mostly succeed in pushing the entrants out of the market and apparently dissuade the majority of experienced rivals from entering.

These observations largely match the theoretical predictions, except for the prevalence of entry when theory predicts no entry. There are several potential explanations of the entry behavior. Rivals may initially be completely naive about the possibility of exclusionary pricing. Slightly more sophisticated rivals may be concerned about possible post-entry price reductions, but they may not understand

\footnotetext{
${ }^{20}$ There are a few instances where the incumbent leaves the market, making the entrant a monopolist. The average price in these situations is 54.8 which is basically identical to the rival's monopoly price (55).
} 
how much they need to earn to profitably enter the market. This is plausible as there are three different notions of costs to keep track off: variable costs (30 per unit), fixed operating costs (250) and opportunity costs (50). Finally, rivals may be aware of the potential problem, but hope that the incumbent tries to get away with high prices. All of these possibilities are consistent with the observation that entry becomes far less common over time, because subjects learn that entry is usually not profitable.

\section{$3.2 \quad$ Policy Effects}

The results in the previous section show that above-cost predatory pricing occurs under Laissez-faire. They also suggest that fear of such behavior may discourage entry. However, one cannot be sure about this last claim without comparing the Laissez-faire results to a situation in which exclusionary pricing is impossible or restricted. In this section, we provide such a benchmark. We compare a laissezfaire regime with the Brooke Group, Baumol and Edlin policies, respectively. The Edlin policy is particularly important, because it directly limits above-cost predatory pricing by design: if we see more entry in EDLIN than in L'FAIRE, this will show that fear of price cuts by the incumbent prevents entry in the latter case.

Policy can potentially affect market outcomes via two channels. First, policy may influence the entry decision and therefore the frequency of the three market structures (PreEntry, Duopoly, PostExit). Second, policy may affect prices under each of the market structures. In the following, we will isolate the two effects. We start by showing how the policies affect prices under each market structure. Then, we investigate the policy effects on market structure.

\subsubsection{Prices Under Different Market Structures}

PreEntry: Theory predicts that in L'FAIRE, BROOKE, and BAUMOL, the incumbent will charge the monopoly price of 50 in PreEntry, because its price does not affect entry. In EDLIN the incumbent will charge 46 in order to deter entry.

Figure 4 bins the observed prices into three categories. The intervals are motivated by our theoretical analysis. The intermediate category $[47,53]$ contains the monopoly price as well as slightly higher and lower prices; this category is what 
theory predicts we should expect under the first three treatments. Low prices in $[0,46]$ are those that qualify as entry-deterring under the Edlin rule, by which we mean that, for these prices, the incumbent can ensure that the entrant loses money in the following period. High prices in $[54,80]$ are not predicted by our theoretical model for any treatment.

Figure 4 shows that in L'FAIRE, BAUMOL, and BROOKE, the incumbent generally prices in the intermediate category at or near the monopoly level. The average price we observe in the PreEntry structure is close to the monopoly price of 50 in the first three treatments, with 49.6 in L'FAIRE, 49.1 in BROOKE, and 50.0 in BAUMOL. EDLIN produces substantially different results with 44.9 percent of the observations in the low price bin. The average price is at 46.2 , very close to the theoretical prediction. ${ }^{21}$ Thus, firms systematically respond to the Edlin rule and frequently choose entry-deterring prices as expected.

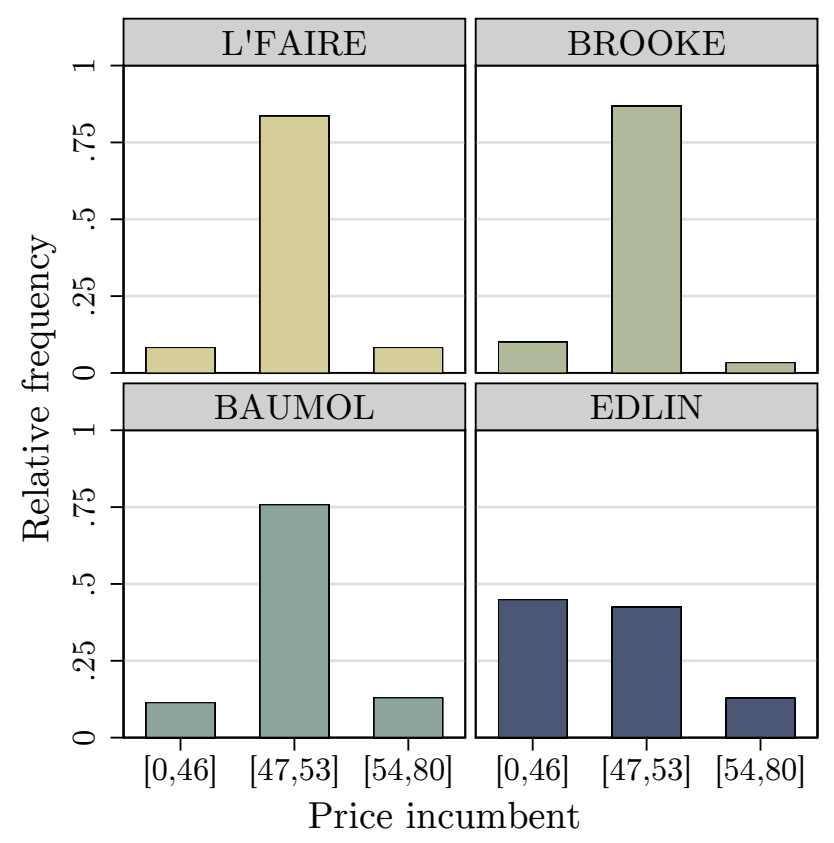

Figure 4: Distribution of incumbent prices in the structure PreEntry.

\footnotetext{
${ }^{21}$ The differences across all treatments are significant at $p=.011$ (Kruskal-Wallis test). The bilateral difference between EDLIN and L'FAIRE (BAUMOL) is significant at $p=.033(p=.002)$. For two-group tests, we report $p$-values of exact Wilcoxon rank-sum tests. All tests use the independent matching group averages as observations.
} 
Duopoly: Advocates of strict predatory pricing rules want to reduce the frequency of predatory pricing, while Laissez-faire advocates worry about the consumer loss from discouraging price wars. As there is some entry in all treatments, we can investigate the policy effects on exclusionary pricing.

The bars in the left panel of Figure 5 show the frequency of predatory pricing (37 or lower) by incumbents in the periods where they compete with the rival. We find that the frequency is 75.3 percent in L'FAIRE, 69.5 percent in BROOKE, 66.1 percent in BAUMOL and 50.3 percent in EDLIN. In EDLIN, the frequency is significantly lower than in any of the other three treatments. ${ }^{22}$

The lower frequency of predatory pricing in EDLIN is clearly due to the policy restrictions. When incumbents are not restricted by the rule, we observe a very high frequency of above-cost predatory prices (88.0 percent) even in EDLIN. ${ }^{23}$

These observations are very much in line with what we would expect. In L'FAIRE and BROOKE, nothing prevents the incumbents from setting above-cost predatory prices, and it is optimal for them to do so. In BAUMOL, firms can set duopoly prices as they want, but they must worry about the adverse consequences for allowable post-exit prices. Finally, in EDLIN, incumbents are simply not allowed to pursue exclusionary pricing after high pre-entry prices.

The right panel of Figure 5 is essentially the mirror image of the left panel. It shows the market prices in Duopoly. L'FAIRE and BROOKE produce the most competitive prices, followed by BAUMOL and EDLIN. ${ }^{24}$ The differences between adjacent bars are not significant, but the comparison between EDLIN and the first two treatments is $(p<.004)$. In addition, if we pool the observations from L'FAIRE and BROOKE and test against BAUMOL, the differences become significant at $p=.043$. Consequently, while BROOKE does not have an effect, the two other policies have the downside that they lead to higher prices than L'FAIRE when entry happens.

\footnotetext{
${ }^{22} p<.003$, Wilcoxon rank-sum test on average frequency in the matching group. All other bilateral comparisons are insignificant $(p>.128)$.

${ }^{23}$ Incumbents are not restricted when either no rule applies to them or the rule allows predatory prices.

${ }^{24}$ In all treatments, prices are clearly above the entrant's marginal cost. This is in contrast to the results of Boone et al. (2012), who find prices close to the marginal cost of the less efficient firm, while other experimental studies on Bertrand oligopolies with asymmetric costs find prices above the Nash equilibrium (Dugar and Mitra, 2016; Argenton and Müller, 2012). An important difference between our design and these studies is that, in our case, the entrant faces fixed costs.
} 

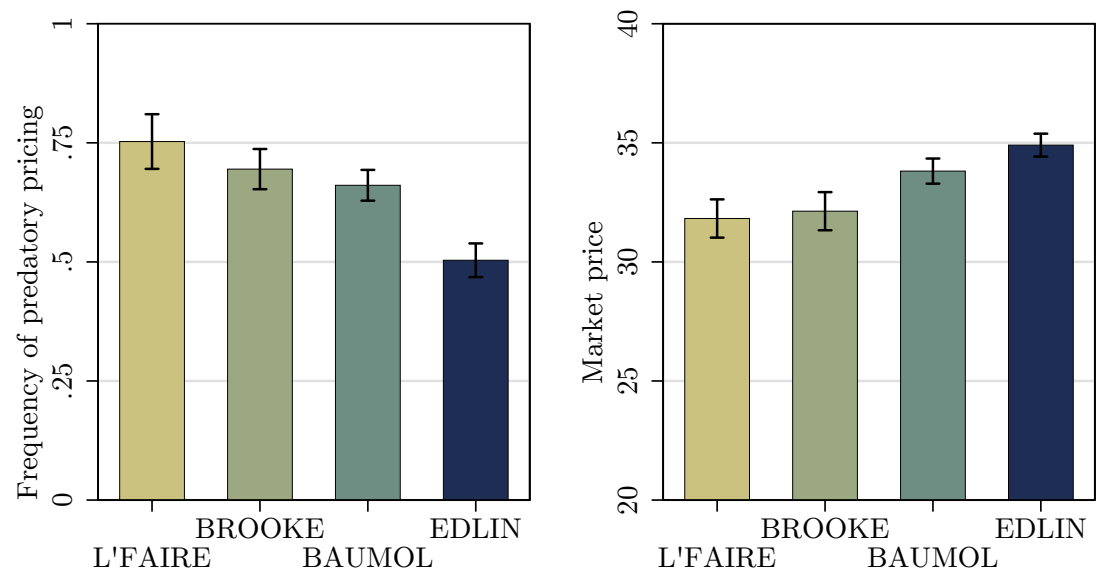

Figure 5: Prices in Duopoly. Left panel: frequency of predatory pricing by the incumbents across treatment. Right panel: market prices across treatment. Spikes indicate standard errors, calculated with clustering on matching group.

PostExit: In the structure PostExit, the firm remaining in the market has a monopoly and does not face the threat of market entry. Unless restricted, we would expect that such a firm sets the monopoly price. This is indeed the case: incumbents' average prices are very close to 50 with 78 percent or more at exactly 50 in L'FAIRE, BAUMOL, and EDLIN. ${ }^{25}$ In BAUMOL, we observe significantly lower prices due to the price cap. Virtually all firms (97.8 percent) price at the Baumol price cap whenever it applies. The average PostExit price of the incumbents is $38.7 .^{26}$

Result 2. In PreEntry and PostExit, average prices are close to the monopoly level. Lower prices only occur in EDLIN in PreEntry and in BAUMOL in PostExit. In Duopoly, above-cost predatory pricing is frequent in L'FAIRE, BROOKE, and BAUMOL. EDLIN substantially reduces the frequency of above-cost predatory pricing. When both firms are in the market, L'FAIRE and BROOKE yield the most competitive pricing.

\footnotetext{
${ }^{25}$ In the cases where the incumbent exited, we observe prices close to the monopoly price of the entrant of 55 .

${ }^{26}$ The differences to all other treatments are highly significant.
} 
By and large, the results are consistent with the theoretical predictions. Incumbents that are not challenged by potential entry or know they can adjust prices freely after entry have no incentive to deviate from the monopoly price. It takes restrictions on post-entry price reductions (EDLIN) to induce low pre-entry prices, whereas low post-exit prices only obtain when price increases after exit are prohibited (BAUMOL). In duopoly cases, above-cost predatory pricing is expected in all treatments - with the obvious caveat that in EDLIN, the incumbent might be limited in its ability to price low by its earlier pricing decisions.

\subsubsection{Market Structure Effects}

Result 2 shows how the price effects of policy depend on market structure. However, the overall policy effects will also depend on how often each of the three market structures will arise under each policy. We now show how policy affects these frequencies.

Entry: We first compare the overall entry frequency under the different policies. Recall that theory predicts no entry under any rule in equilibrium. In addition, there is no entry in L'FAIRE, BROOKE, or BAUMOL in any subgame equilibrium, even after off-equilibrium prices. In EDLIN, there is no entry on the equilibrium path, but entry occurs following incumbent prices above 46 .

Unlike predicted, we observe entry in all regimes. In period 2, we observe that 51.8 percent enter in L'FAIRE, and 45.2 percent in BROOKE. BAUMOL (60.6 percent) seems to encourage entry, presumably because rivals hope that the incumbent is reluctant to fight: anticipating the Baumol restriction, incumbents know they have to continue to price low after exit. As suggested by our off-equilibrium analysis, we find the highest fraction of entry decisions in EDLIN with 72.7 percent. ${ }^{27}$

Incumbent Price and Entry: We will now show that policy not only affects the frequency of entry, but also the circumstances under which entry occurs. According to Proposition 3, under the Edlin rule, entry is the best response to prices above the entry-deterring price of 46, whereas under the other rules, entry is usually a poor choice regardless of the incumbent's pre-entry price.

\footnotetext{
${ }^{27}$ Differences across all treatments are significant at $p=.005$, differences between EDLIN and L'FAIRE or BAUMOL are significant at $p<.003$.
} 


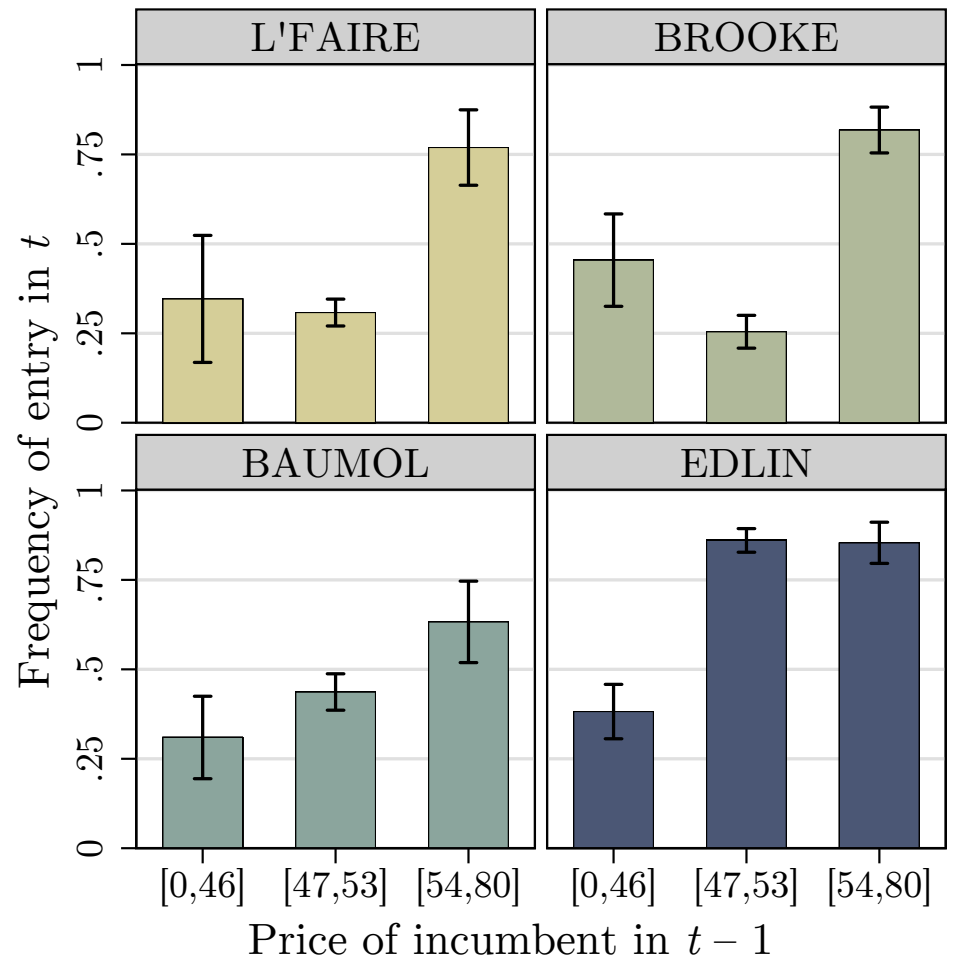

Figure 6: Frequency of entry for different incumbent prices in the previous period. For this figure, we use all periods in which the rival can enter. We use the same bins for the incumbent price in the previous period as in Figure 4. Spikes indicate standard errors (with clustering on matching group).

Figure 6 shows the fraction of rivals entering the market, conditional on the incumbent's price in the previous period. In all treatments, above-monopoly prices seem to encourage entry, ranging from 63.3 percent in BAUMOL to 85.4 percent in EDLIN. However, entry behavior differs across policies in the intermediate price range. For prices near the monopoly level, entry is quite rare in L'FAIRE and BROOKE (30.8 and 25.4 percent), and somewhat higher in BAUMOL (43.7 percent). For all these treatments, there is a significant difference between entry after monopoly prices (middle bin) and after above-monopoly prices (right bin) at $p<.032$. In stark contrast, EDLIN produces more than twice as much entry as the other treatments after incumbent prices near the monopoly level, with 86.0 percent of rivals entering the market. The entry frequency for low incumbent prices 
is similar in all treatments. To conclude, incumbent prices above the monopoly price encourage entry in all treatments, whereas prices close to the monopoly price typically discourage entry just as much as lower prices, unless the Edlin rule is in place.

The differences in the circumstances under which rivals enter are closely related to what happens to them after entry. In L'FAIRE, 67.0 percent of the entrants are undercut by the incumbent in the first period after entry, and around half of the entrants who experience undercutting after entry exit immediately. The numbers for BROOKE and BAUMOL are similar, with slightly less undercutting but even more exit. On the other hand, in EDLIN, 78 percent of the entrants undercut the incumbent in the first period after entry, but nevertheless 50.9 percent exit. This shows that entry is typically of a hit-and-run type. Contrary to the L'FAIRE and BROOKE cases, entry in EDLIN is often profitable.

Frequency of Market Structures: Table 1 shows the percentage of periods in which the market is in a given structure in each of the four treatments.

Table 1: Frequency of market structures

\begin{tabular}{lrrrr}
\hline Structure & L'FAIRE & BROOKE & BAUMOL & EDLIN \\
\hline PreEntry & 55.1 & 59.1 & 47.3 & 37.0 \\
Duopoly & 27.7 & 22.9 & 25.2 & 31.4 \\
PostExit & 17.3 & 18.0 & 27.5 & 31.6 \\
\hline
\end{tabular}

Notes. Percentage of periods with a given market structure, separated by treatment. In addition to the cases defined at the beginning of Section 3, category PreEntry also contains those Period 4 interactions for which the rival has not previously entered in the round under consideration, and PostExit contains the few cases when both firms exited the market.

The main insights are as follows. In line with our observations on the frequency of entry, we find that PreEntry is most common in L'FAIRE and BROOKE, and particularly rare in EDLIN. Duopoly periods are more common in EDLIN than in the remaining treatments. However, the particularly anti-competitive PostExit situation is most frequent for EDLIN. ${ }^{28}$

\footnotetext{
${ }^{28}$ It is also quite frequent for BAUMOL, but, in this case, the adverse effect is mitigated by the Baumol rule. The treatment differences are significant $\left(p=.000, \chi^{2}\right.$ test with correction for clusters).
} 
Result 3. We observe frequent market entry in all treatments, particularly in EDLIN and, to a slightly lesser extent, in BAUMOL. Consistent with the theory of off-equilibrium path behavior, entry in EDLIN mainly happens in cases where the incumbent does not set entry-deterring prices. With experience, entry drops considerably in L'FAIRE and BROOKE, but much less so in the two other treatments.

The relative entry frequencies match the differences in protection given to entrants under the different policies. In L'FAIRE and BROOKE, there is no protection whatsoever, in EDLIN, it is provided directly by the downward price freeze for the incumbent. In BAUMOL, there is some indirect protection, because post-entry price reductions are costly for the incumbent if the rival exits.

\subsection{Dynamics}

For the analysis so far, we considered all seven rounds of the game. Investigating the dynamics across the seven rounds gives us an indication of whether play converges towards the theoretical predictions once subjects become more experienced with the strategic environment. We first study the dynamic in prices and then in market structure.

Prices: Throughout the experiment, average prices in PreEntry for L'FAIRE, BROOKE, and BAUMOL are very close to the monopoly price, in particular, in the last round, when more than 85 percent of the incumbents set the monopoly price. Model (1) in Table 2 shows the results of OLS estimates for the incumbents' preentry prices in the first period (with clustered standard errors). Prices in EDLIN are significantly lower than in the omitted case (L'FAIRE) and in BAUMOL $(p=.006) .{ }^{29}$ The differences between EDLIN and the other treatments become stronger later in the experiment, as is shown in Model (2), where we estimate treatment-specific time trends. EDLIN shows a highly significant negative time trend, while the other three treatments do not. A closer look at the data shows that incumbents' prices in EDLIN are initially close to the monopoly price, but then drop sharply to averages around 45 in rounds $5-7$. In the first half of the rounds (1-4), 32.8 percent of the incumbents choose entry-deterring prices in PreEntry. In the second half of the

\footnotetext{
${ }^{29}$ The difference between EDLIN and BROOKE is insignificant, which is due to relatively similar prices in early rounds.
} 
rounds, this percentage increases to 59.2 percent. This pattern suggests that it took some time for the subjects to learn how to react to the strategic incentives provided by the Edlin rule.

Model (3) in Table 2 explains market prices in Duopoly. Prices are significantly higher in BAUMOL and EDLIN than in L'FAIRE and BROOKE, and the overall time trend is significantly negative, suggesting that competition becomes fiercer in later rounds. In Model (4), we qualify this observation by estimating separate time trends: the point estimate is negative in all four treatments, but significant only in L'FAIRE.

Table 2: Incumbents' prices in PreEntry and market prices in Duopoly

\begin{tabular}{|c|c|c|c|c|}
\hline & \multicolumn{2}{|c|}{ Price in $t=1$ (PreEntry) } & \multicolumn{2}{|c|}{ Market price in Duopoly } \\
\hline & (1) & $(2)$ & (3) & (4) \\
\hline BROOKE & $\begin{array}{r}-1.405 \\
(0.976)\end{array}$ & $\begin{array}{r}-3.548 \\
(2.888)\end{array}$ & $\begin{array}{c}0.255 \\
(1.093)\end{array}$ & $\begin{array}{r}-0.616 \\
(1.837)\end{array}$ \\
\hline BAUMOL & $\begin{array}{c}0.300 \\
(0.921)\end{array}$ & $\begin{array}{r}-1.669 \\
(2.010)\end{array}$ & $\begin{array}{r}2.080^{*} \\
(0.933)\end{array}$ & $\begin{array}{l}1.274 \\
(1.264)\end{array}$ \\
\hline EDLIN & $\begin{array}{r}-2.679^{*} \\
(1.044)\end{array}$ & $\begin{array}{r}-1.340 \\
(1.785)\end{array}$ & $\begin{array}{l}3.216^{* *} \\
(0.906)\end{array}$ & $\begin{array}{l}1.865 \\
(1.225)\end{array}$ \\
\hline Round & $\begin{array}{r}-0.123 \\
(0.163)\end{array}$ & & $\begin{array}{r}-0.277^{*} \\
(0.124)\end{array}$ & \\
\hline Round $\times$ L'FAIRE & & $\begin{array}{r}-0.281 \\
(0.198)\end{array}$ & & $\begin{array}{r}-0.527^{*} \\
(0.259)\end{array}$ \\
\hline Round $\times$ BROOKE & & $\begin{array}{c}0.254 \\
(0.522)\end{array}$ & & $\begin{array}{r}-0.260 \\
(0.333)\end{array}$ \\
\hline Round $\times$ BAUMOL & & $\begin{array}{c}0.211 \\
(0.258)\end{array}$ & & $\begin{array}{r}-0.281 \\
(0.215)\end{array}$ \\
\hline Round $\times$ EDLIN & & $\begin{array}{c}-0.616^{* *} \\
(0.203)\end{array}$ & & $\begin{array}{r}-0.136 \\
(0.211)\end{array}$ \\
\hline Constant & $\begin{array}{l}50.598 \\
(1.011) \\
\end{array}$ & $\begin{array}{c}51.232 \\
(1.335) \\
\end{array}$ & $\begin{array}{l}32.733 \\
(0.825) \\
\end{array}$ & $\begin{array}{c}33.553 \\
(0.937) \\
\end{array}$ \\
\hline$F$-test & 2.8 & 3.9 & 6.4 & 3.8 \\
\hline Prob $>F$ & 0.042 & 0.003 & 0.001 & 0.003 \\
\hline$R^{2}$ & 0.024 & 0.033 & 0.047 & 0.048 \\
\hline$N$ & 798 & 798 & 1720 & 1720 \\
\hline
\end{tabular}

Notes: OLS estimates. Dependent variables in model (1) and (2): incumbent's price in period 1. Model (3) and model(4): market prices in Duopoly. Independent variables: treatment dummies, round, interactions, and a dummy for incumbent. Robust standard errors, clustered on matching group, in parentheses. ${ }^{*} p<0.05,{ }^{* *} p<0.01$. 
Market structure: Figure 7 shows the fraction of games in which the rival enters at some point across the seven rounds. Across all treatments, we observe that there is less entry when subjects gain experience with the game. The drop is particularly strong in L'FAIRE and BROOKE. In both cases, the fraction of games in which the rival enters drops from close to 100 percent in the first round to less than 50 percent in the second half of the experiment (rounds $5-7$ ). While there is also a drop in entry as experience increases, entry remains substantially more frequent in BAUMOL (63.0 percent) and in particular in EDLIN (86.9 percent) in the second half of the rounds. ${ }^{30}$

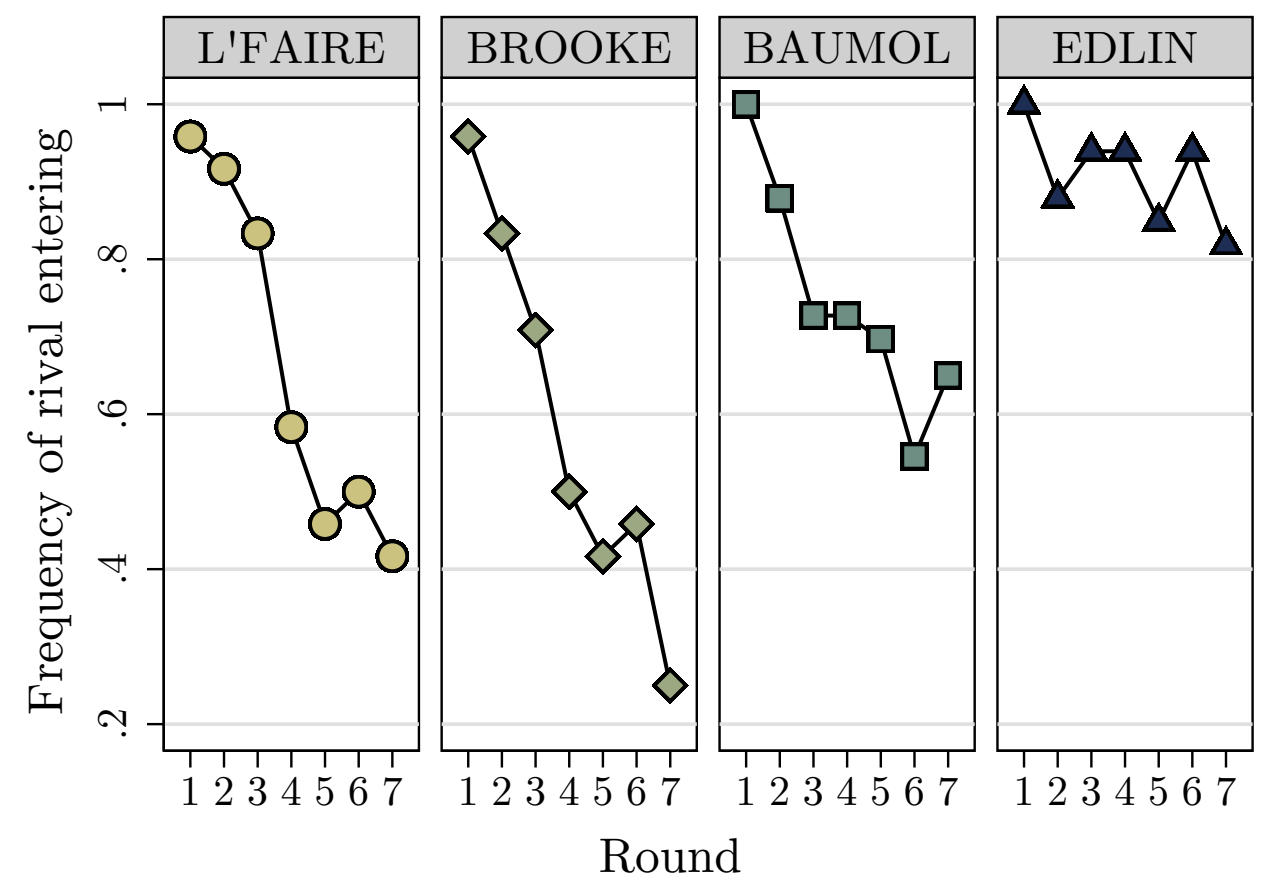

Figure 7: Frequency of rival entry across the seven rounds and by treatment.

The observations confirm the impression that, at least in L'FAIRE and BROOKE, subjects initially enter because they ignore or at least underestimate the risk of exclusionary pricing, whereas they tend to assess it correctly in later rounds. For the other policies, it is less clear that entry is a mistake, because the rules offer

\footnotetext{
${ }^{30}$ The difference in entry between inexperienced and experienced subjects is significant for L'FAIRE $(p=.008)$, BROOKE $(p=.016)$, and BAUMOL $(p=.010)$, but not for EDLIN $(p=.129)$, Wilcoxon signed-rank test on matching group averages.
} 
some protection for the entrant. Consequently, there is a smaller reduction in entry with increasing experience.

Result 4. Over the course of the seven periods we observe no time trend in the prices when incumbents hold the monopoly, with the exception of PreEntry in EDLIN, in which subjects converge on average to the entry-deterring prices only in the second half of the rounds. Price wars in Duopoly tend to become fiercer in later rounds. As subjects gain experience with the game, entry becomes less frequent in all treatments, but the drop is much more pronounced in the treatments which offer least protection for the entrant (L'FAIRE and BROOKE).

The dynamics across the seven rounds suggests that some of the strategic incentives set by the different policies require experience to become effective. In our welfare analysis below we therefore put more emphasis on the results of the games with experienced subjects and we will restrict some of the analysis to the second half of the experiment, i.e., rounds $5-7$.

\subsection{Welfare Implications of the Policies}

The results presented so far clearly illustrate that two of the three alternative policies result in significantly different market outcomes than the laissez-faire approach. While the outcome of BROOKE is very similar to L'FAIRE, EDLIN results in lower prices prior to entry and BAUMOL results in substantially lower prices after exit. Moreover, the latter two policies encourage entry. We now summarize the welfare implications of these results.

\subsubsection{Consumer Surplus and Welfare for Fixed Market Structures}

Figure 8 shows how our previous price observations translate into results on consumer surplus, conditional on market structure. The bars show the average consumer surplus from rounds 5-7, where subjects have experience with the policies. ${ }^{31}$ In PreEntry, the consumer surplus is very close to the predicted monopoly consumer surplus of 450 in all but one treatment. The exception is EDLIN, in which

\footnotetext{
${ }^{31}$ The results of rounds 1-4 are qualitatively identical, with the only notable difference that the advantage of EDLIN in PreEntry is not yet as pronounced as in rounds 5-7.
} 


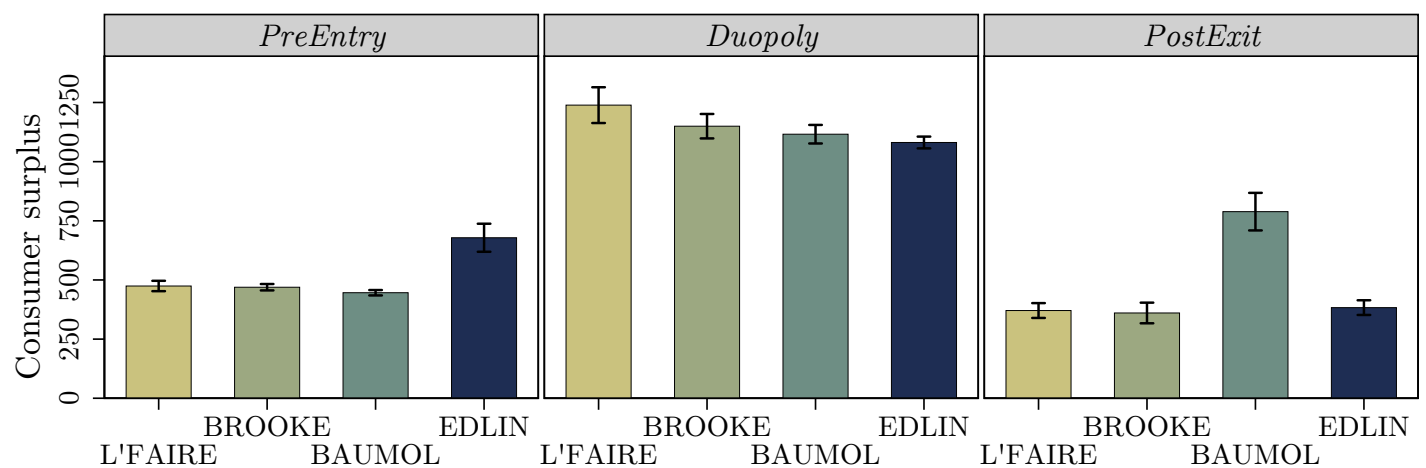

Figure 8: Consumer surplus in rounds 5-7. Bars show average consumer surplus, spikes indicate standard errors (with clustering on matching group).

the predicted price prior to entry is 46 resulting in a consumer surplus of 578 . The observed consumer surplus is even higher with 678. ${ }^{32}$ In Duopoly, we observe the most competitive outcomes in L'FAIRE and BROOKE, but the overall treatment differences are not significant ( $p=.155$, Kruskal-Wallis test). In PostExit, only BAUMOL results in a consumer surplus significantly and substantially higher than in the unregulated monopoly.

In terms of total welfare (consumer surplus plus producer surplus net of fixed operating costs) results in rounds 5-7 are very similar as for consumer surplus only: EDLIN is significantly more efficient than the other treatments in PreEntry, and the same is true for BAUMOL in PostExit. For Duopoly, on the other hand, EDLIN is significantly less efficient than the other treatments. Apart from the duplication of fixed costs, the reason for this difference is that, under the Edlin rule, it is more likely that the entrant serves the market than in the other treatments, which results in efficiency losses due to the higher marginal cost.

\subsubsection{Overall Comparison}

Finally, we analyze the overall welfare implications, taking into account that policies also affect market structure and not only prices conditional on market structure. Table 3 shows the average consumer surplus and welfare over the four periods of the game. The resulting numbers aggregate the policy effects on pricing and

\footnotetext{
${ }^{32}$ The difference between EDLIN and each of the other three treatments is highly significant $(p<.002$, Wilcoxon rank-sum tests $)$.
} 
Table 3: Consumer surplus and welfare across treatment

\begin{tabular}{lrrrrrr}
\hline & \multicolumn{2}{c}{ Consumer surplus } & & \multicolumn{2}{c}{ Welfare } \\
\cline { 2 - 3 } \cline { 5 - 6 } \cline { 5 - 6 } & Rounds 1-4 & Rounds 5-7 & & Rounds 1-4 & Rounds 5-7 \\
\hline L'FAIRE & 702 & 597 & & 1050 & 1123 \\
BROOKE & 697 & 533 & & 1096 & 1101 \\
BAUMOL & 738 & 664 & & 1117 & 1118 \\
EDLIN & 649 & 697 & & 970 & 1049 \\
\hline
\end{tabular}

Notes. Average consumer surplus and welfare across the four periods of the respective game, for Rounds $1-4$ and Rounds 5-7 of the experiment.

market structure. The theoretical benchmarks with monopoly in all four periods and no entry result in a consumer surplus of 450 and a welfare of 1150 . This is the prediction for all treatments but EDLIN, in which case there are three periods of entry-deterring prices and monopoly prices in the fourth period, resulting in an average consumer surplus of 546 and a welfare of 1234 . In rounds $1-4$, there are no significant overall differences across treatments in consumer surplus $(p=.105$, Kruskal-Wallis test). In rounds 5-7, differences become significant $(p=.005)$ with BAUMOL and, even more so, EDLIN generating more consumer surplus than the other two treatments. For welfare, however, we observe significant differences across the four treatments in rounds $1-4(p=.000)$, with the lowest welfare in EDLIN. When subjects gain experience in EDLIN (rounds 5-7), the differences in welfare across treatments become insignificant $(p=.229)$.

Result 5. Edlin's policy proposal dominates a laissez-faire approach prior to entry, and Baumol's policy does so after exit. Both policies come at the cost that competition tends to be weaker in duopoly. The overall welfare effects depend on the frequency of these market structures. EDLIN is favorable from a consumer perspective when firms are sufficiently experienced with the rule. Overall welfare is lowest in EDLIN, while the other three treatments produce very similar results.

The low consumer surplus in L'FAIRE and BROOKE is essentially in line with what we would expect and mostly driven by the lack of entry and the high preentry prices. The higher consumer surplus in BAUMOL is not predicted by the SPE. It directly reflects the greater frequency of entry and the lower post-exit prices. Finally, the high consumer surplus in EDLIN reflects both the frequent entry and the low pre-entry prices. 
The relatively low total welfare in EDLIN is the downside of particularly pronounced (off-equilibrium) entry. Entry not only leads to duplication of fixed costs, but also to relatively low variable profits reflecting (undesired) production by the high-cost rival as well as (desired) competitive pressure. This leads to the observed deviations from the theoretical predictions.

\section{Discussion and Conclusion}

Economists, lawyers, and policy makers debate whether post-entry price cuts discourage entry and whether we should care. This paper studies such price cuts in a multi-period interaction between a low-cost monopolistic incumbent and a high-cost potential entrant. We compare a laissez-faire setting with three different policy interventions: the legal standard of the Brooke Group rule, according to which below-cost pricing is prohibited; a policy that prohibits certain postentry price cuts (Edlin, 2002); and a policy that prohibits post-exit price increases (Baumol, 1979).

In subgame-perfect equilibrium, there is no entry in any of these settings. Under the Laissez-faire, Brooke Group and Baumol policies, this is true even though the incumbents choose monopoly prices. Under the Edlin rule, the incumbent prices below the monopoly level because this is needed to prevent entry. In theory, nothing resembling predatory pricing occurs on the equilibrium path. In this sense, predatory pricing is a unicorn from a theoretical perspective.

The observations of the experiment differ from our theoretical predictions. Neither L'FAIRE nor BROOKE - the current U.S. policy - place any relevant constraints on post-entry price cuts. Despite this, there is some entry in both treatments, which is followed by price wars and often exit. Both pre-entry and post-exit prices tend to monopoly levels. In both L'FAIRE and BROOKE, the incumbent frequently responds to entry with prices too low for the entrant to break even. As these prices are low enough to induce exit and discourage entry, they are exclusionary and we call them above-cost predation. Such pricing is no unicorn. It is prevalent. ${ }^{33}$

\footnotetext{
${ }^{33}$ Such a pattern fits the anecdotal evidence in Bolton et al. (2000) who report that, in the six years following the Brooke Group decision, plaintiffs have not prevailed in any of the 39 reported cases in the federal court.
} 
Edlin's (2002) restrictions on post-entry price cuts substantially encourage entry, particularly in later rounds when people understand the game better. Put differently, the anticipated price cuts in L'FAIRE and BROOKE must have discouraged entry and been exclusionary in practice. The incumbent's price cutting not only induces exit, but its prospect discourages entry. In EDLIN, prices are substantially lower prior to entry. This makes sense. The incumbent cannot discourage entry with the threat to price low after entry unless it prices low prior to entry. While the massive entry in EDLIN benefits consumers, it has the downside that it involves a replication of fixed cost and higher cost production by the entrant.

Baumol's post-exit price restrictions lead to an intermediate frequency of entry and lower post-exit prices. However, pre-entry prices are as high as in L'FAIRE and BROOKE, and duopoly prices are slightly higher than in those cases.

The welfare comparison in the theoretical model is trivial. Because there is no entry in any treatment and pricing in the Edlin policy is low while it is monopoly in the other three regimes, Edlin's policy dominates whether from a consumer or a total welfare perspective. The experimental analysis, however, reveals a more complex picture. Since policies differ with respect to the effects on entry, as well as on duopoly and post-exit prices, a full welfare judgment needs to take all these effects into account. For the specific parameter values of our model, these effects mean that both lenient approaches to above-cost predation, L'FAIRE and BROOKE, and BAUMOL all perform well with respect to total welfare and substantially better that EDLIN. From a consumer perspective, however, EDLIN is preferable.

There is scope for exploring the robustness of our analysis. Most directly, it would be instructive to vary some of our main assumptions. Apart from considering smaller cost differences and other policy parameters, it would seem particularly important to explore longer games under different assumptions for the length of protection by the Edlin and Baumol rules. Moreover, one could explore the efficacy of these policies in a situation of learning by doing such as Cabral and Riordan (1994) and Besanko et al. (2010, 2014), where it is possible for an inefficient entrant to eventually be efficient. 


\section{References}

Argenton, C. and W. Müller (2012). Collusion in experimental Bertrand duopolies with convex costs: The role of cost asymmetry. International Journal of Industrial Organization 30(6), 508-517.

Baker, J. (1994). Predatory pricing after Brooke Group: An economic perspective. Antitrust Law Journal 62(3), 585-603.

Baumol, W. J. (1979). Quasi-permanence of price reductions: A policy for prevention of predatory pricing. Yale Law Journal 89(1), 1-26.

Besanko, D., U. Doraszelski, and Y. Kryukov (2014). The economics of predation: What drives pricing when there is learning-by-doing? American Economic Review 104(3), 868-897.

Besanko, D., U. Doraszelski, Y. Kryukov, and M. Satterthwaite (2010). Learning-bydoing, organizational forgetting, and industry dynamics. Econometrica 78(2), 453508.

Bock, O., I. Baetge, and A. Nicklisch (2014). hroot: Hamburg registration and organization online tool. European Economic Review 71, 117-120.

Bolton, P., J. F. Brodley, and M. H. Riordan (2000). Predatory pricing: Strategic theory and legal policy. Georgetown Law Journal 88, 2239-2330.

Bolton, P. and D. S. Scharfstein (1990). A theory of predation based on agency problems in financial contracting. American Economic Review 80(1), 93-106.

Boone, J., M. J. L. Aylwin, W. Müller, and A. R. Chaudhuri (2012). Bertrand competition with asymmetric costs: Experimental evidence. Economics Letters 117(1), 134-137.

Cabral, L. M. B. and M. H. Riordan (1994). The learning curve, market dominance, and predatory pricing. Econometrica 62(5), 1115-1140.

Cabral, L. M. B. and M. H. Riordan (1997). The learning curve, predation, and antitrust. Journal of Industrial Economics 45(2), 155-169.

Capra, M. C., J. K. Goeree, R. Gomez, and C. A. Holt (2000). Predation, asymmetric information and strategic behavior in the classroom: An experimental approach to the teaching of industrial organization. International Journal of Industrial Organization 18(1), 205-225.

Chiaravutthi, Y. (2007). Predatory pricing with the existence of network externalities in the laboratory. Information Economics and Policy 19(2), 151-170.

Dugar, S. and A. Mitra (2016). Bertrand competition with asymmetric marginal costs. 
Economic Inquiry 54(3), 1631-1647.

Easterbrook, F. H. (1981). Predatory strategies and counterstrategies. University of Chicago Law Review 48(2), 263-337.

Edlin, A. S. (2002). Stopping above-cost predatory pricing. Yale Law Journal 111(4), 941-991.

Edlin, A. S. (2012). Predatory pricing. In E. Elhauge (Ed.), Research Handbook on Economics of Antitrust. Edward Elgar.

Eilat, A., D. Gilo, and G. Sagi (2016). Loyalty discounts, exclusive dealing and bundling: Rule of reason, quasi-per-se, price-cost test, or something in between? Journal of Antitrust Enforcement 4 (2), 345-380.

Elzinga, K. G. and D. E. Mills (2001). Predatory pricing and strategic theory. Georgetown Law Journal 89(8), 2475-2494.

Ezrachi, A. and D. Gilo (2009). Are excessive prices really self-correcting? Journal of Competition Law $\&$ Economics 5(2), 249-268.

Ezrachi, A. and D. Gilo (2010). Excessive pricing, entry, assessment, and investment: Lessons from the Mittal litigation. Antitrust Law Journal 76 (3), 873-897.

Farrell, J. and G. Saloner (1986). Installed base and compatibility: Innovation, product preannouncements, and predation. American Economic Review 76 (5), 940-955.

Fischbacher, U. (2007). z-Tree - Zurich toolbox for readymade economic experiments. Experimental Economics 10(2), 171-178.

Fudenberg, D. and J. Tirole (1986). A "signal jamming" theory of predation. RAND Journal of Economics 17(4), 366-377.

Gaudin, G. and D. Mantzari (2016). Margin squeeze: An above-cost predatory pricing approach. Journal of Competition Law \& Economics 12(1), 151-179.

Genesove, D. and W. P. Mullin (2006). Predation and its rate of return: The Sugar Industry, 1887-1914. RAND Journal of Economics 37(1), 47-69.

Goeree, J. K. and R. Gomez (1998). Predatory pricing in the laboratory. Draft, University of Virginia.

Gomez, R., J. K. Goeree, and C. A. Holt (2008). Predatory pricing: Rare like a unicorn? In C. R. Plott and V. L. Smith (Eds.), Handbook of Experimental Economics Results, Volume 1, Chapter 22, pp. 178-184. Elsevier B.V.

Goolsbee, A. and C. Syverson (2008). How do incumbents respond to the threat of entry? Evidence from the major airlines. Quarterly Journal of Economics 123(4), $1611-1633$.

Harrington, J. E. (1986). Collusion and predation under (almost) free entry. Interna- 
tional Journal of Industrial Organization 7(3), 381-401.

Harrison, G. W. (1988). Predatory pricing in a multiple market experiment: A note. Journal of Economic Behavior and Organization 9(4), 405-417.

Hovenkamp, H. (2005). Exclusion and the Sherman Act. The University of Chicago Law Review 72(1), 147-164.

Huck, S., H.-T. Normann, and J. Oechssler (2004). Two are few and four are many: Number effects in experimental oligopolies. Journal of Economic Behavior \& Organization 53(4), 435-446.

Isaac, R. M. and V. L. Smith (1985). In search of predatory pricing. Journal of Political Economy 93(2), 320-345.

Jung, Y. J., J. H. Kagel, and D. Levin (1994). On the existence of predatory pricing: An experimental study of reputation and entry deterrence in the chain-store game. RAND Journal of Economics 25(1), 72-93.

Kreps, D. M. and R. Wilson (1982). Reputation and imperfect information. Journal of Economic Theory 27(2), 253-279.

Lerner, J. (1995). Pricing and financial resources: An analysis of the disk drive industry, 1980-88. Review of Economics and Statistics 77(4), 585-598.

Milgrom, P. and J. Roberts (1982). Predation, reputation, and entry deterrence. Journal of Economic Theory 27(2), 280-312.

Motta, M. and C. Fumagalli (2013). A simple theory of predation. Journal of Law and Economics 56(3), 595-631.

Normann, H.-T. and R. Ricciuti (2009). Laboratory experiments for economic policy making. Journal of Economic Surveys 23(3), 407-432.

Podolny, J. M. and F. M. Scott Morton (1999). Social status, entry and predation: The case of British Shipping cartels 1879-1929. Journal of Industrial Economics 47(1), $41-67$.

Popofsky, M. S. (2006). Defning exclusionary conduct: Section 2, the rule of reason, and the unifying principle underlying antitrust rules. Antitrust Law Journal 73(2), $435-482$.

Saloner, G. (1987). Predation, mergers, and incomplete information. RAND Journal of Economics 18(2), 165-186.

Salop, S. C. (2005). Anticompetitive overbuying of power buyers. Antitrust Law Journal 72(2), 669-715.

Salop, S. C. (2006). Exclusionary conduct, effect on consumers, and the flawed profitsacrifice standard. Antitrust Law Journal 73(2), 311-374. 
Scharfstein, D. (1984). A policy to prevent rational test-marketing predation. RAND Journal of Economics 15(2), 229-243.

Scott Morton, F. M. (1997). Entry and predation: British Shipping cartels 1879-1929. Journal of Economics and Management Strategy 6(4), 697-724. 


\title{
Online Appendix
}

\section{Hunting Unicorns? Experimental Evidence on Predatory Pricing Policies}

\author{
Aaron Edlin, Catherine Roux, Armin Schmutzler, Christian Thöni
}

\section{A Proofs}

We now provide careful statements of our theoretical results and proofs. We start by formulating two tie-breaking rules. ${ }^{1}$

(T1) In any situation where both firms charge the same price, but a profitable downward deviation for exactly one firm is feasible, this firm wins the entire market (and becomes dominant).

The condition addresses two types of situations. First, it applies to cases where one firm is at its marginal cost (and thus cannot profitably reduce its price). ${ }^{2}$ Second, it is relevant if one firm is at the Edlin constraint (and thus cannot reduce its price at all). The tie-breaking rule reflects the idea of a suitable discrete approximation.

Moreover, we have a tie-breaking rule regarding participation:

(T2) If firm $\mathrm{H}$ is indifferent between entering and not entering given the subsequent subgame strategies, it will not enter.

We maintain these tie-breaking assumptions throughout the paper.

\footnotetext{
${ }^{1}$ Our instructions assume that, for ties, firms share the profits 50-50. For the equilibrium analysis, we nevertheless need tie-breaking rules.

${ }^{2}$ In this case, the tie-breaking rule generates the standard textbook outcome that both firms charge at $c_{H}$, but firm $L$ receives the entire demand. The relevant implication of this outcome that firm $L$ serves the entire market at price $c_{H}$ can be generated more precisely in an equilibrium where firm $H$ mixes on an interval of prices $c_{H}$ and higher (see Blume 2003, and Kartik 2011).
} 


\section{A.1 Laissez-Faire and Brooke Group Games}

\section{A.1.1 Proof of Proposition 1}

The proof is identical for both games. There is a unique equilibrium strategy profile such that

(i) both firms play their respective monopoly price in subgames when they are alone in the market;

(ii) both firms choose the Bertrand duopoly price $\left(c_{H}\right)$ in subgames when both firms are present;

(iii) firm $L$ participates for every history; firm $H$ does not participate for any history.

Clearly, in period 4, the described monopoly strategies are optimal; the strategy profile in the duopoly case is the unique pure-strategy equilibrium of the asymmetric Bertrand game. Anticipating this, firm $H$ only participates in period 4 if firm $L$ has previously exited. In period 3, suppose $L$ is the monopolist. It anticipates being the monopolist in period 4 independent of pricing, so it sets $p^{M}\left(c_{L}\right)$. The argument is analogous if $H$ is the monopolist (meaning that $L$ has exited). If both firms are present, they anticipate that firm $L$ will be the monopolist in period 4 , independent of pricing in period 3. Thus, they set prices without taking period 4 into account, and the short-term Bertrand equilibrium emerges in period 3. Anticipating this pricing behavior, it is clear that only firm $L$ is expected to earn positive net profits in the market, unless firm $H$ is the monopolist in period 3 . This gives the entry decision. The argument in the preceding periods is analogous.

\section{A.2 Edlin}

We first formulate a version of Proposition 2 that describes the equilibrium strategies in more detail. This result clearly implies the statement in the main text. 


\section{A.2.1 Re-Statement of Proposition}

Proposition 1. The Edlin Game has an SPE described in (i)-(ix) below. This equilibrium is not unique, but any SPE in pure strategies generates the same outcome.

(i) Firm $L$ participates in periods $t \leq 3$ for arbitrary histories after which it has not previously exited. In period $4, L$ exits if and only if $p_{3}^{L}>p^{*}$ and $H$ has not previously entered (or $L$ was dominant in period 3 ).

(ii) $H$ participates in period $t$ only if it has not previously exited and (a) L has exited, or (b) $L$ was dominant in period $t-1$ with $p_{t-1}^{L}>p^{*}$.

(iii) In periods in which $L$ is a monopolist, it sets prices as follows: If $H$ has not yet entered in any period $t \leq 3, L$ sets $p_{t}^{L}=p^{*}$ (entry deterrence). Otherwise, $L$ sets $p_{4}^{L}=p^{M}\left(c_{L}\right)=50$.

(iv) If $L$ has previously exited, Player $H$ sets $p_{t}^{H}=p^{M}\left(c_{H}\right)=55$.

(v) If both firms participate in Period 4 and neither firm was dominant in period $3, p_{4}^{L}=p_{4}^{H}=c_{H}$ (and firm L takes the market given the tie-breaking rule).

(vi) Suppose both firms participate in Period 4 and $L$ was dominant in period 3:

(a) If $0.8 p_{3}^{L} \in\left[0, c_{H}\right], p_{4}^{L}=p_{4}^{H}=c_{H}$ and firm $L$ takes the market;

(b) If $0.8 p_{3}^{L} \in\left(c_{H}, 80\right], p_{4}^{L}=p_{4}^{H}=0.8 p_{3}^{L}$ and firm $H$ takes the market. ${ }^{3}$

(vii) Suppose both firms participate in Period 4 and $H$ was dominant in period 3 :

(a) If $0.8 p_{3}^{H} \in\left[0, c_{H}\right], p_{4}^{L}=p_{4}^{H}=c_{H}$

(b) If $0.8 p_{3}^{H} \in\left(c_{H}, 80\right], p_{4}^{L}=p_{4}^{H}=0.8 p_{3}^{H}$;

Firm $L$ takes the market in both cases.

(viii) If both firms participate in periods $t=2,3$, and $L$ was dominant in period $t-1$, price-setting is as follows:

(a) If $0.8 p_{t-1}^{L} \in\left[0, c_{H}\right]$, then $p_{t}^{L}=p_{t}^{H}=0.8 p_{t-1}^{L}$ and firm $L$ takes the market;

(b)If $0.8 p_{t-1}^{L} \in\left(c_{H}, p^{M}\left(c_{H}\right)\right]$, then $p_{t}^{L}=p_{t}^{H}=0.8 p_{t-1}^{L}$ and firm $H$ takes the market;

(c) If $0.8 p_{t-1}^{L} \in\left(p^{M}\left(c_{H}\right), 80\right]$, then $p_{t}^{L} \geq 0.8 p_{t-1}^{L} ; p_{t}^{H}=p^{M}\left(c_{H}\right)$, and firm $H$ takes the market.

(ix) If both firms participate in Period 3 and firm $H$ was dominant in period 2,

\footnotetext{
${ }^{3}$ In the special case that $0.8 p_{3}^{L}=c_{H}$, the firms share the market, so that neither firm is dominant.
} 
price-setting is as follows:

(a) If $0.8 p_{2}^{H} \in\left[0, c_{H}\right]$, then $p_{3}^{L}=p_{3}^{H}=c_{H}$;

(b) If $0.8 p_{2}^{H} \in\left(c_{H}, p^{*}\right]$, then $p_{3}^{L}=p_{3}^{H}=0.8 p_{2}^{L}$;

(c) If $0.8 p_{2}^{H} \in\left(p^{*}, 80\right]$, then $p_{3}^{L}=p^{*} ; p_{3}^{H} \geq 0.8 p_{2}^{H}$.

Firm $L$ takes the market in all three cases.

(x) If both firms participate in Period 3 and neither firm was dominant in period 2 , both firms set $c_{H}$ and firm $L$ takes the market.

\section{A.2.2 Proof of Proposition 3}

We define the quasi-cost of a firm with cost type $\theta \in\{L, H\}$ that was dominant in period $t-1$ in period $\mathrm{t}$ as $\widehat{c}_{\theta}=\max \left(0.8 p_{t-1}^{\theta}, c_{\theta}\right){ }^{4}$

Existence Period 4: For period 4, consider pricing: Obviously, setting the monopoly price is optimal for a monopolist as the competitor cannot be present in the future (see (iii) and (iv)). In any case where both firms are present in the last period, the game corresponds essentially to a static asymmetric Bertrand game with marginal costs of the dominant firm replaced with the quasi-marginal cost $\widehat{c}_{\theta}$. By arguments similar to those from the Bertrand game (together with the tie-breaking rule) a last-period price profile is a subgame equilibrium if and only if both firms price at $\max \left(\widehat{c}_{H}, \widehat{c}_{L}\right)$. The winner is the unconstrained firm by the tie-breaking rule. Together, these arguments show (v)-(vii). They also show (iii) and (iv) for $t=4$.

For period 4, consider participation. Anticipating the pricing behavior of $L$, $H$ chooses to participate only if it is possible to break even in the last period, which requires one of the two conditions (a) and (b) in (ii): For (a), $H$ earns the monopoly profit in period 4; for (b) she earns a non-negative net profit by setting $p_{4}^{H}=0.8 p_{3}^{L}$. If neither of these conditions hold, undercutting of firm $L$ does not lead to positive net profits, so that entry is not profitable.

Anticipating the pricing behavior of $H$, Firm $L$ only exits whenever she cannot set an entry-deterring price; that is, whenever $L$ was dominant in period 3 with $p_{3}^{L}>p^{*}$.

\footnotetext{
${ }^{4}$ The motivation for calling this a quasi-cost is that the constraint to price above $0.8 p_{t-1}^{\theta}$ has a similar effect on behavior as the constraint not to price below marginal cost.
} 
Period 3 Pricing: In any subgame starting after the period 3 participation decisions, players anticipate that the competitor chooses the equilibrium strategy in period 4 after any period 3 pricing decision. In particular, firm $H$ anticipates that, if firm $L$ is in the market in period 3, it will stay and set prices in period 4 such that firm $H$ cannot obtain a positive net profit unless firm $L$ is dominant in period 3 with $p_{3}^{L}>p^{*}$; similarly, firm $L$ anticipates that firm $H$ will participate in period 4 only if $p_{3}^{L}>p^{*}$ and firm $H$ was dominant in period 3 . With this in mind, consider the pricing decisions in period 3 .

Suppose first both firms are in and $H$ was dominant in period 2 (see ix). First, let $0.8 p_{2}^{H} \leq c_{H}$ : With the proposed prices (and the tie-breaking rule), firm $L$ earns a profit of $\left(c_{H}-c_{L}\right) D\left(c_{H}\right)$ in period 3. It induces exit of firm $H$ and earns monopoly profits in period 4 . Lower prices of Firm $L$ in period 3 would reduce the period 3 profits of firm $L$ without resulting in more profit in period 4. Any prices above $c_{H}$ would lead to zero profits in period 3 and, at most the monopoly profit in period 4. Thus, firm $L$ is best-responding. Firm $H$ earns no profits, but cannot avoid this given that firm $L$ undercuts in period 3 (and thereby also sets an entry-deterring price for period 4$)$.

Second, let $0.8 p_{2}^{H} \in\left(c_{H}, p^{*}\right]$ : With the proposed prices (and the tie-breaking rule), firm $L$ earns a profit of $\left(0.8 p_{2}^{H}-c_{L}\right) D\left(0.8 p_{2}^{H}\right)$ in period 3. It induces exit of firm $H$ in period 4 and earns monopoly profits in period 4 . Lower prices in period 3 would reduce period 3 profits without resulting in more profit in period 4 . Higher prices in period 3 would lead to zero profits in period 3 and, at most the monopoly profit in period 4. Thus, firm $L$ is best-responding. Firm $H$ earns no profits, but cannot avoid this.

Finally, let $0.8 p_{2}^{H}>p^{*}$. Firm $H$ is constrained by the requirement that $p_{3}^{H} \geq$ $0.8 p_{2}^{H}>p^{*}$. For any such price of firm $H$, by following the proposed strategy of setting $p_{3}^{L}=p^{*}$, firm $L$ obtains a gross profit of $\left(p^{*}-c_{L}\right) D\left(p^{*}\right)$ in period 3 ; moreover $L$ induces exit of firm $H$ and earns the monopoly profit in period 4 . This is a best response for $L$ : For any higher price, firm $H$ would participate in period 4 , so that firm $L$ would earn at most one monopoly profit (in period 3 ). For any lower price, firm $L$ would still prevent entry and earn the monopoly profit in period 4 , but period 3 profits would be lower than $\left(p^{*}-c_{L}\right) D\left(p^{*}\right)$. Firm $H$ earns zero profits, but it cannot avoid this. 
Next, suppose both firms are in and $L$ was dominant in period 2 (viii): First consider $0.8 p_{2}^{L} \leq c_{H}$ : In the proposed equilibrium both firms set $c_{H}$. If $0.8 p_{2}^{L}<c_{H}$, by the tie-breaking rule, firm $L$ wins in this period (with the maximum possible period 3 profit given $p_{3}^{H}=c_{H}$ ); as $c_{H}<p^{*}$, she obtains the monopoly profit in period 4 . Thus, $L$ is best-responding. Firm $H$ earns zero profits, but cannot avoid this; thus $H$ is also best-responding. If $0.8 p_{2}^{L}=c_{H}$, the argument is essentially the same, except that the two firms share the market in period 3 (as both firms are constrained below, the tie-breaking rule does not apply).

Second, suppose $0.8 p_{2}^{L} \in\left(c_{H}, p^{*}\right]$ : In the proposed equilibrium, firm $H$ undercuts firm $L$ and is thus dominant. Hence, in the next period firm $H$ does not enter according to her strategy, and firm $L$ earns the monopoly profit. Firm $H$ is bestresponding, because she cannot avoid having zero profits in period 4 (as $p_{3}^{L}=$ $0.8 p_{2}^{L} \leq p^{*}$ ) and her profit in period 3 is maximal given the behavior of firm $L$. Firm $L$ is also best-responding: She earns the monopoly profit in period 4; moreover, given her constraint and the behavior of firm $H$ she cannot prevent losing in period 3 .

Third, let $0.8 p_{2}^{L} \in\left(p^{*}, p^{M}\left(c_{H}\right)\right]$ : In the proposed equilibrium, firm $H$ undercuts $L$ in period 3. Firm $L$ earns the monopoly profit in period 4 . It cannot undercut firm $H$ in period 3; so it is best-responding. Firm $H$ obtains the maximal possible profit in this period, $\left(0.8 p_{2}^{L}-c_{H}\right) D\left(0.8 p_{2}^{L}\right)-F$, but no profit in period 4 . The only potentially profitable alternative would be to set a higher price and thereby avoid undercutting $L$. Then $L$ would exit in period 4 (as $0.8 p_{2}^{H}>p^{*}$ ) given its strategy, and firm $H$ would earn $\left(p^{M}\left(c_{H}\right)-c_{H}\right) D\left(p^{M}\left(c_{H}\right)\right)-F$ in period 4 , but would also have to pay the additional fixed cost in period 3. Thus, $H$ is best-responding if $\left(0.8 p_{2}^{L}-c_{H}\right) D\left(0.8 p_{2}^{L}\right)-F \geq\left(p^{M}\left(c_{H}\right)-c_{H}\right) D\left(p^{M}\left(c_{H}\right)\right)-2 F$. The right-hand side is 125 . The condition holds for $0.8 p_{2}^{L} \in[37.679,70.811]$, and, in particular, in the interval $\left(p^{*}, p^{M}\left(c_{H}\right)\right]=(44.544,50]$ under consideration.

Fourth, suppose $0.8 p_{2}^{L} \in\left(p^{M}\left(c_{H}\right), 80\right]$. Firm $H$ earns the monopoly profit in period 3 , and firm $L$ earns the monopoly profit in period 4 . Firm $L$ cannot undercut firm $H$ in period 3; thus it is best responding. Firm $H$ cannot prevent that firm $L$ takes the market in period 4, unless it gives up on winning in period 3 and thus becoming dominant. Winning immediately, and thus not incurring the fixed cost in period 4 is preferable. 


\section{Now suppose both firms are in and neither was dominant in the previous period $(\mathrm{x})$ :}

In this case, both firms are free to set arbitrary prices. The argument is as in an asymmetric Bertrand equilibrium, taking into account that firm $H$ will exit in the next period and firm $L$ will win the market.

Finally, consider situations with only one firm is in the market (iii) and (iv) for $\mathbf{t}=\mathbf{3}$. If firm $H$ is monopolist, then this is because firm $L$ has exited. There is no re-entry threat; firm $H$ thus obtains the monopoly profit in two periods by applying her strategy, which clearly is optimal. If firm $L$ is monopolist, this could be because firm $H$ has exited or because it has never entered. In the former case, there is no re-entry threat; firm $L$ thus obtains the monopoly profit in two periods by applying her strategy, which clearly is optimal. In the latter case, firm $L$ has to take into account that firm $H$ will enter in period 4 if and only if $p_{3}^{L}>p^{*}$. In the proposed equilibrium, $L$ deters entry by setting $p_{3}^{L}=p^{*}$. She thus earns a positive profit $\left(p^{*}-c_{L}\right) D\left(p^{*}\right)-F$ if she adheres to the equilibrium strategy. This is clearly the best possible response among those that deter entry. The best way not to deter entry is to set $p_{3}^{L}=p^{M}\left(c_{L}\right)$. This way, however, firm $L$ only obtains the monopoly profit once, which is less than with the proposed equilibrium behavior.

Next, consider participation decisions in period 3.

First, consider player $L$. According to the proposed equilibrium strategies, she stays in the market. If she was not dominant in period 2 , she expects a positive profit in both periods, so staying is optimal. If she was dominant in period 2 with $p_{2}^{L}<p^{*}$, this is also true, because she expects firm $H$ to exit. If she was dominant with $p_{2}^{L}>p^{*}, L$ expects that $H$ will enter and undercut in period 3 , so that $L$ will earn no profit in period 3, and she will pay the fixed cost of 300 . However, in period 4, she will be the monopolist and earn the net profit 600 . Thus, staying is a best response.

Second, consider player $H$. Clearly, if $L$ has exited, participation (as proposed by the strategy) is optimal for $H$. If $L$ is in period $3, H$ participates only if $L$ was dominant in period 2 with $p_{2}^{L}>p^{*}$. By staying if $p_{2}^{L}>p^{*}, H$ earns positive net profits in period 3. She will exit thereafter, but participating in period 3 is nevertheless profitable. By not participating if $p_{2}^{L} \leq p^{*}$, she earns zero profits in 
periods 3 and 4 . Given the strategy of player $L$, she cannot avoid this.

The argument in period 2 is analogous to the argument for period 3. The only slightly larger difference concerns the case that $L$ is in and $0.8 p_{1}^{L} \in$ $\left(p^{*}, p^{M}\left(c_{H}\right)\right]$ : In the proposed equilibrium, firm $H$ undercuts $L$ in period 2 and Firm $L$ earns the monopoly profit in periods 3 and 4 . $L$ cannot undercut firm $H$ in period 2; so it is best-responding. Firm $H$ obtains the maximal possible profit in this period given the price of firm $L,\left(0.8 p_{1}^{L}-c_{H}\right) D\left(0.8 p_{1}^{L}\right)-F$, but no profit in periods 3 and 4 . The alternative would be to avoid undercutting $L$. However, then $L$ would still remain in the market in period 3 given its strategy, and firm $H$ would earn at most $\left(p^{M}\left(c_{H}\right)-c_{H}\right) D\left(p^{M}\left(c_{H}\right)\right)-F$ in period 3 (and no profit in period 4). The deviation is thus even less attractive than in the corresponding situation in period 3 for $0.8 p_{2}^{L} \in\left(p^{*}, p^{M}\left(c_{H}\right)\right]$.

In Period 1, the only pricing deviation for firm 1 worth considering is that it chooses the monopoly price. Doing this yields a short term gain of $650-620.23=29.77$, but a loss of the monopoly profit (650) in the next period. Thus, the proposed strategy profile is a subgame perfect equilibrium.

Uniqueness We already saw that we cannot hope for more than outcome uniqueness. Clearly, any SPE must involve the above-described behavior in Period 4.

\section{Consider pricing in Period 3.}

Suppose both firms are in and $H$ was dominant in period 2.

First suppose $0.8 p_{2}^{H} \in\left[0, p^{*}\right]$. Consider an arbitrary equilibrium price candidate $p_{3}^{H} \in\left(c_{L}, p^{*}\right]$. Then it is always the unique best response of firm $L$ to undercut marginally: Given period 4 behavior, this yields the monopoly profit in period 4 and, given $p_{3}^{H}$, the maximum possible profit in period 3. Thus, any equilibrium with $p_{3}^{H} \in\left(c_{L}, p^{*}\right]$ must have $p_{3}^{L}=p_{3}^{H}$ and firm $L$ taking the market. Moreover, any such equilibrium must have $p_{3}^{H}=\widehat{c}_{H}$, for otherwise firm $H$ could profitably deviate downwards. Clearly, there can be no equilibrium with $p_{3}^{H}>p^{*}$ : In this case, firm $H$ could profitably undercut whenever $p_{3}^{L}>0.8 p_{2}^{H}$. If $p_{3}^{L} \leq 0.8 p_{2}^{H}$, firm $L$ could profitably deviate by increasing the price to $p^{*}$. Finally, equilibria with $p_{3}^{H} \leq c_{L}$ can clearly not exist. Thus, all equilibria must contain prices in period 3 as described in (ix)

Second suppose $0.8 p_{2}^{H}>p^{*}$. Then it is clearly the unique best response for firm $L$ 
to set $p_{3}^{L}=p^{*}$. As (ix) allows for arbitrary behavior of $H$ that is consistent with the Edlin constraint, there can be no other equilibrium than those mentioned in (ix).

\section{Suppose both firms are in and $L$ was dominant in period 2 .}

Suppose $0.8 p_{2}^{L} \in\left[0, c_{H}\right]$. There can be no equilibrium with $p_{3}^{L}>p^{*}$, as firm $L$ would thereby giving up period 4 monopoly profits, which it could avoid by setting $p^{*}$ (this deviation could potentially lower period 3 profits, but never by an amount that would not make it worthwhile).

There can be no equilibrium with $p_{3}^{H}>c_{H}$ If firm $H$ wins in such an equilibrium and $p_{3}^{H}<p^{*}$, firm $L$ could undercut and earn a positive profit in period 3 (and still the monopoly profit in period 4 ). Now suppose firm $L$ wins in such an equilibrium. We already saw there can be no equilibrium such that $p_{3}^{L}>p^{*}$. Thus suppose $p_{3}^{L} \leq p^{*}$. Then $H$ can increase profits by marginally undercutting. Clearly there can be no equilibrium with $p_{3}^{H}=p_{3}^{L}=p^{*}$.

There cannot be an equilibrium with $p_{3}^{\theta} \in\left[0, c_{L}\right)$ for at least one $\theta \in\{L, H\}$ either. As firm $H$ would earn (avoidable) negative gross profits, there can be no equilibrium with $p_{3}^{H} \leq p_{3}^{L}$ and $p_{3}^{H} \in\left[c_{L}, c_{H}\right)$. There can be no equilibrium with $p_{3}^{L}<p_{3}^{H}$ and $p_{3}^{H} \leq p^{*}$, as firm $L$ could increase profits by increasing price (while still inducing exit). Finally, consider $p_{3}^{H} \in\left[c_{L}, c_{H}\right)$ and $p_{3}^{H}>p_{3}^{L}$. Firm $L$ could profitably increase prices.

If $p_{3}^{H} \leq p_{3}^{L}$, firm $L$ could profitably undercut firm $H$. Thus, the only remaining possibility is $p_{3}^{H}=p_{3}^{L}=c_{H}$.

Suppose $0.8 p_{2}^{L} \in\left(c_{H}, p^{*}\right]$. For any allowable $p_{3}^{L} \in\left[0.8 p_{2}^{L}, p^{*}\right)$, firm $H$ knows that it will earn zero profits in period 4 no matter what it does in period 3 . Thus, it has the unique best response to undercut marginally, so that $p_{3}^{H}=p_{3}^{L}$. Clearly, there can be no such equilibrium with $p_{3}^{L}>0.8 p_{2}^{L}$, as both firms could profitably undercut. Thus, we must indeed have $p_{3}^{L}=p_{3}^{H}=0.8 p_{2}^{L}$. Next consider $p_{3}^{L}>p^{*}$. If $p_{3}^{L}<p_{3}^{H}$, firm $L$ would become dominant in period 3 and thus give up the monopoly profit in period 4 . It could thus profitably deviate to $p^{*}$. If $p_{3}^{H}<p_{3}^{L}$, firm $H$ would benefit from increasing its price slightly. If $p_{3}^{H}=p_{3}^{L}, H$ would benefit from undercutting marginally. Finally, suppose $p_{3}^{L}=p^{*}$ and $0.8 p_{2}^{L}<p^{*}$. If $p_{3}^{H}<p_{3}^{L}$, firm $H$ would benefit from increasing its price slightly. If $p_{3}^{H} \geq p_{3}^{L}, H$ would benefit from undercutting. 
Suppose $0.8 p_{2}^{L} \in\left(p^{*}, p^{M}\left(c_{H}\right)\right]$. Given the restrictions of $L$, firm $H$ can always undercut marginally and thereby secure a profit of $\left(p_{3}^{L}-c_{H}\right) D\left(p_{3}^{L}\right)-F$. This is always a best response: Not undercutting would mean that she would induce exit of firm $L$, so that she would earn the monopoly profit in period 4 , but she would have to pay the fixed cost twice. By previous arguments, not undercutting is not a profitable deviation. Pricing lower than $p_{3}^{L}$ would mean profit losses in period 3, without any compensating gains. Finally, an equilibrium with prices above $0.8 p_{2}^{L}$ cannot exist: Firm $H$ could always increase profits by reducing its price, without any compensating losses.

Suppose $0.8 p_{2}^{L} \in\left(p^{M}\left(c_{H}\right), 80\right]$. As (viii) does not restrict the strategy of $L$ beyond the Edlin restriction, we only check whether there can be another price of $H$ than $p^{M}\left(c_{H}\right)$ in any equilibrium. For any price of $L$, this would have to lead at least to one monopoly profit of firm $H$ (as $H$ can always secure this by setting $\left.p^{M}\left(c_{H}\right)\right)$. Given the strategy of $L$ in period 4 , getting a gross monopoly profit in period 4 is only possible for $H$ if it does not undercut $L$ in period 3 who then cannot avoid that firm $H$ enters in period 4. However, any such strategy of firm 3 means that it wins only one (gross) monopoly profit, but has to pay the fixed costs twice. As the alternative of winning the monopoly profit immediately and paying the fixed cost only once is always available (independent of the behavior of $L$ ), pricing above $L$ in period 3 cannot be a best response.

\section{Remaining Arguments}

The above arguments on pricing in Period 3 imply the statements on participation (Part (i) and (ii) of Proposition 4). The argument for the uniqueness of pricing behavior in Period 2 duopolies is similar as for Period 3 except that it is simpler because the incumbent is always dominant. Thus behavior from period 2 on in any equilibrium is as described in Proposition 4. As the first-period behavior of firm L described in Proposition 4 is strictly optimal given the reactions in periods 2 and following, there can be no other equilibrium.

\section{A.3 Baumol}

We start by presenting a version of Proposition 3 that specifies the strategies in more detail. We then prove the result. 


\section{A.3.1 Re-Statement of Proposition 3}

In the Baumol case, we will occasionally invoke a tie-breaking rule which applies in specific constellations when neither firm prices at its quasi-cost. It deals with situations where no firm wants to let the other firm win (so as to avoid being constrained in the next period), whereas the other firm is happy to win (and will exit in the next period).

(T3) Suppose in $t=2,3$ both firms charge the same price, but neither firm prices at its quasi-cost. Fix continuation strategies in $t+1$ for both firms. Suppose firm $i$ prefers leaving the market to $j$ in period $t$ rather than taking the market (and conversely for $j$ ). Then $j$ wins the market.

Proposition 2. The Baumol Game has a continuum of SPE described below, and all equilibria have these properties: ${ }^{5}$

Periods $t=3,4$ : If a firm $\theta$ is alone in the market after the other firm has previously exited, and $\theta$ was dominant in the period $s$ in which the other firm exited, $\theta$ sets $p_{\theta}^{\beta}=\min \left(p^{M}\left(c_{\theta}\right), p_{s}^{\theta}\right)$. In any other situation such that $\theta$ is alone in the market, it sets $p^{M}\left(c_{\theta}\right)$. If both firms are in the market, they set $p_{t}^{H}=p_{t}^{L}=c_{H}$. Only L participates unless ( $i) L$ has exited in period $s<t$ and or (ii) $L$ was dominant in period $t-1$ and $p_{t-1}^{L}<p_{L}^{B}$. In case (i), only $H$ participates if (a) firm $L$ exited before there was a duopoly or (b) L exited after a duopoly period in which $p_{s-1}^{H} \geq$ $p_{B}^{H}$; if $p_{s-1}^{H}<p_{H}^{B}$ nobody participates. In case (ii), both firms mix over participation decisions and earn zero expected profits.

Period 2: Everything is as in periods 3 and 4, except in the duopoly situation. Then both firms set arbitrary but identical prices in $\left[c_{H}, \widetilde{p}_{2}\right]$ such that

$$
3\left(\widetilde{p}_{2}-c_{L}\right)\left(80-\widetilde{p}_{2}\right)=2\left(p^{M}\left(c_{L}\right)-c_{L}\right) D\left(p^{M}\left(c_{L}\right)\right)
$$

and firm $H$ takes the market. $\widetilde{p}_{2}$ is approximately 32.679.

$L$ participates and $H$ does not.

Period 1: L participates and sets the monopoly price.

\footnotetext{
${ }^{5}$ For simplicity, we continue to treat the pricing games in the heuristic textbook manner rather than identifying mixed-strategy equilibria as Blume (2003) and Kartik (2011); see footnote 2.
} 


\section{A.3.2 Proof of Proposition 5}

Period 4: The only non-trivial part of the argument concerns the participation subgame in the case that there was a duopoly in period 3 where firm $L$ was dominant with $p_{3}^{L}<p_{L}^{B}$. In this case, it is straightforward to show that there can be no pure-strategy participation equilibrium: If neither firm participates, $H$ can profitably enter. If both firms participate, $H$ earns negative profits. If only $L$ participates, it earns negative profits (as it is forced to price below break even). If only $H$ stays, $L$ would benefit from staying (and undercutting).

However, there is a mixed strategy equilibrium (with zero expected profits) where firm $H$ stays with probability $r=\left\{\frac{\left(p_{3}^{L}-20\right)\left(p_{3}^{L}-80\right)+300}{\left(p_{3}^{L}-20\right)\left(p_{3}^{L}-80\right)+500}\right\}$ and firm $L$ stays with probability $q=\frac{11}{25}$. As usual, this comes from the indifference conditions (between staying and exiting). For firm $L$ this is

$$
r\left(\left(c_{H}-c_{L}\right)\left(80-c_{H}\right)\right)+(1-r)\left(p_{3}^{L}-c_{L}\right)\left(80-p_{3}^{L}\right)-F=0
$$

As Firm $H$ earns the monopoly profit if it participates and $L$ is not participating, indifference between staying and exiting requires

$$
(1-q)\left(p^{M}\left(c_{H}\right)-c_{H}\right)\left(80-p^{M}\left(c_{H}\right)\right)-F=0
$$

Together, these conditions give the above (uniquely defined) mixing probabilities. The function below plots $r$ as a function of $p_{3}^{L}$ : The lower the previous price was, the higher the required participation probability of firm $H$ that makes $L$ want to participate:

\section{Period 3:}

If a firm $\theta$ is alone in the market, because the other firm has previously exited and $\theta$ had a market share of one in the period that the other firm exited, $\theta$ sets $p_{\theta}^{\beta}$. It cannot set a higher price. A lower price will increase losses.

In any other situation such that $\theta$ is alone in the market, it sets $p^{M}\left(c_{\theta}\right)$.

This is obvious.

If both firms are in the market, they set $p_{3}^{H}=p_{3}^{L}=c_{H}$.

Firm $H$ earns nothing, but cannot avoid this.

Firm $L$ earns $2\left(c_{H}-c_{L}\right)\left(80-c_{H}\right)-2 F=400$ this way (because she takes 


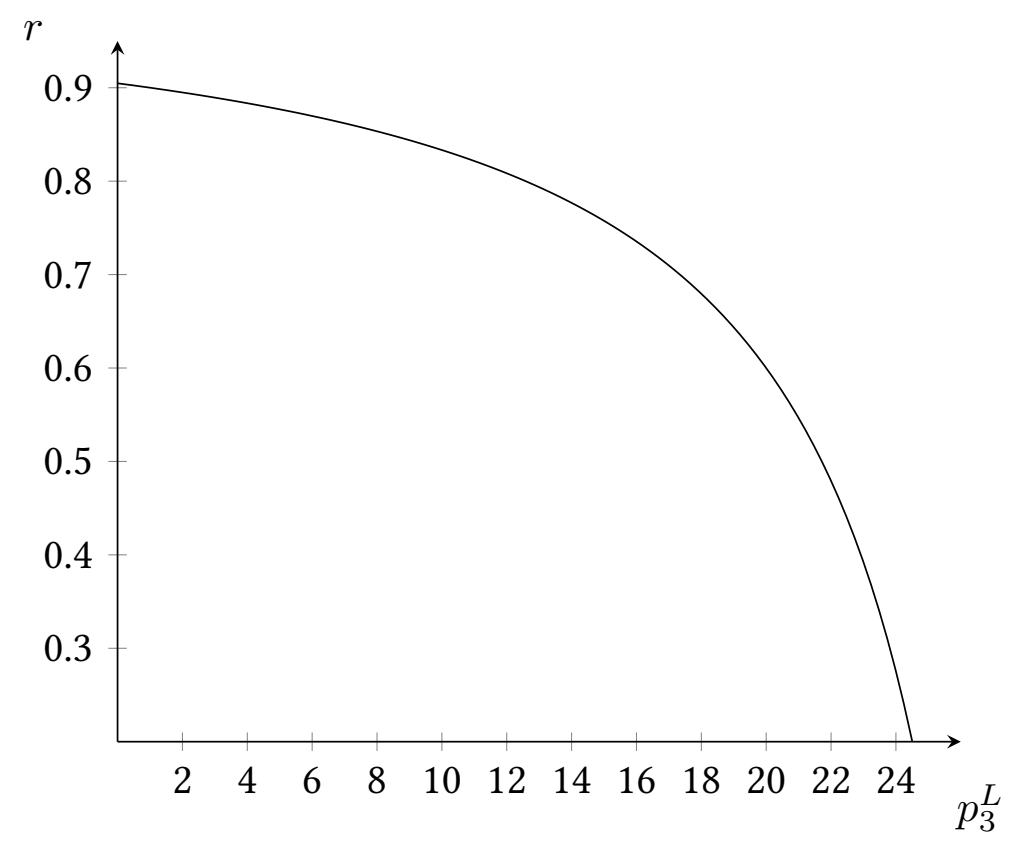

Figure A1: Baumol Game: Mixed strategy of the entrant in Period 4

the market today, she is Baumol constrained tomorrow). The only conceivable profitable deviation would be to let $H$ win today. Then $L$ could set the monopoly profit in period 4 and earn a total profit $\left(p^{M}\left(c_{L}\right)-c_{L}\right) D\left(p^{M}\left(c_{L}\right)\right)-2 F=300$. This deviation is not profitable. The uniqueness argument is similar to standard arguments in the static Bertrand game; in addition, one has to take into account that, for higher prices, $L$ would be prepared to undercut, because the short-term profits would be sufficiently attractive to make up for the (relatively small) longterm losses from the Baumol restriction.

In the participation subgame, there is a unique subgame equilibrium such that only $L$ participates unless (i) $L$ has previously exited in period s and or (ii) firm $L$ was dominant in period 2 with $p_{2}^{L}<p_{L}^{B}$. In case $(i)$, there is a unique subgame equilibrium such that only $H$ participates if $p_{s}^{H} \geq p_{H}^{B}$; otherwise nobody participates. In case (ii), there is no pure-strategy SPE of the period 3 subgame. However, there is an equilibrium where both firms mix over participation decisions. In this equilibrium, both firms earn zero profits.

This is all straightforward except for the mixing equilibrium in participation decisions. Thus consider the case that $L$ was dominant with $p_{2}^{L}<p_{L}^{B}$. 
The argument for why there is no subgame equilibrium is essentially as in period 4: If neither firm participates, $H$ can profitably enter. If both firms participate, $H$ earns negative profits in period 3 (asymmetric Bertrand equilibrium); in the ensuing subgame in period 4 it earns zero on expectation. If only $L$ participates, it earns negative profits (as it is forced to price below break even). If only $H$ stays, $L$ would benefit from staying (and undercutting); thereby earning positive profits in periods 3 and 4 .

Let $t$ be the staying probability of $H$ in period 3. Indifference of firm $L$ requires that $t=\frac{\left(p_{2}^{L}-20\right)\left(p_{2}^{L}-80\right)+300}{\left(p_{2}^{L}-20\right)\left(p_{2}^{L}-80\right)+700}$ (see the plot below)

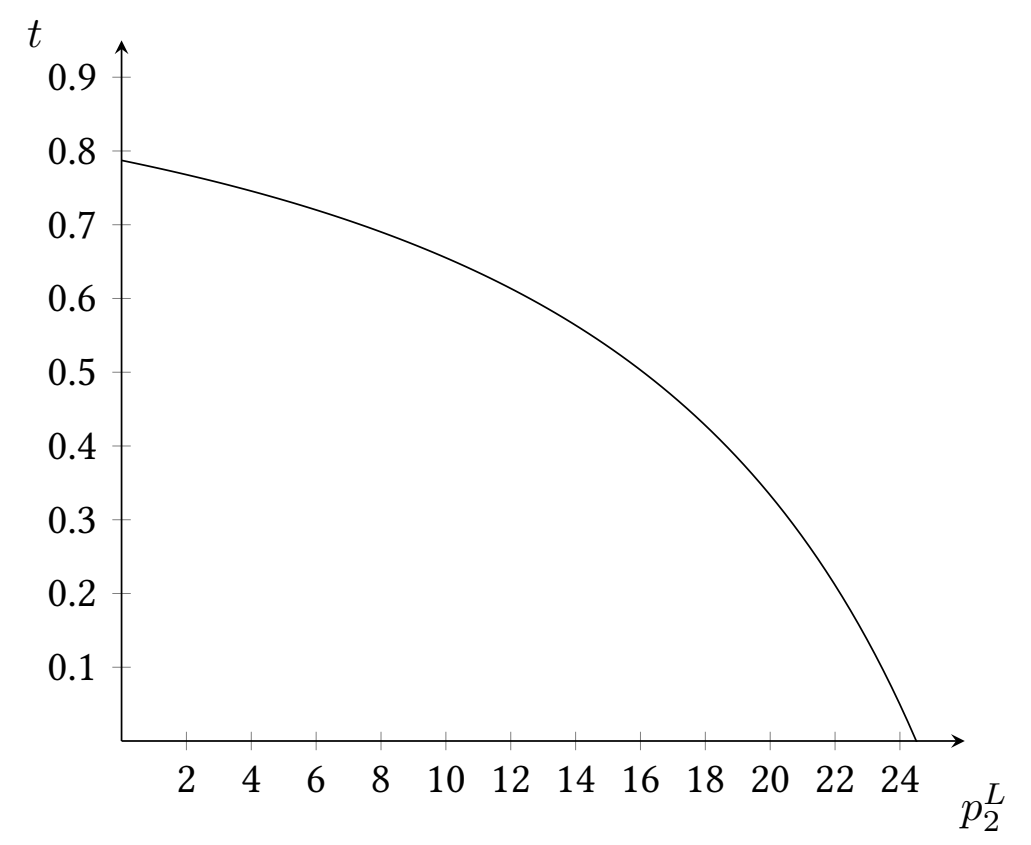

Figure A2: Baumol Game: Mixed strategy of the entrant in Period 3

To see this, suppose $L$ stays. If $H$ does not stay in period 3 , firm $L$ will make losses because of the Baumol constraint, and it will not be present in period 4 to avoid further losses. This gives a profit contribution $(1-t)\left(\left(p_{2}^{L}-20\right)\left(80-p_{2}^{L}\right)-F\right)<0$. If $H$ stays in period 3 , firm $L$ will earn $\left(c_{H}-c_{L}\right)\left(80-c_{H}\right)-F$ in the asymmetric Bertrand equilibrium in period 3. Because $p_{3}^{L}=c_{H}>p_{L}^{B}$, firm $H$ will exit and $L$ will stay, but is constrained to set $p_{4}^{L}=c_{H}$. The expected profits from staying are thus 


$$
(1-t)\left(\left(p_{2}^{L}-20\right)\left(80-p_{2}^{L}\right)-F\right)+t\left(2\left(c_{H}-c_{L}\right)\left(80-c_{H}\right)-2 F\right)
$$

Inserting parameters and setting this equal to zero gives the mixing probability.

If firm $H$ stays, it earns positive profits only if firm $L$ exits in Period 3. (If firm $L$ stays, $H$ will clearly not earn profits in period 3 and it will earn the zero expected MSE profits in period 4).

Let $s$ be staying probability of $L$. If $L$ does not stay, $H$ wins the net monopoly profit in both periods. If $L$ stays in period $3, H$ earns nothing in the resulting asymmetric Bertrand game. As $L$ has then reverted to setting $p_{3}^{L}=c_{H}$ and hence above the Baumol price, $H$ exits thereafter, thus earning a total net profit of -300 in periods 3 and 4 . Thus, the indifference condition is $(1-s)(650)-s(300)=0$, yielding $s=\frac{13}{19}$.

\section{Next consider period 2 .}

In this period, the Baumol constraint has no bite, because there has been no previous duopoly interaction. Thus, any firm that is in the market is free to set its price without any constraints. However, in the duopoly case, the firms will be concerned about constraints that there pricing has on future prices in case of exit of the competitor.

In period 2, consider the suggested prices in $\left[c_{H}, \widetilde{p}_{2}\right]$ : Firm $L$ leaves the market to firm $H$ in period 2 (but pays the fixed cost) and then earns twice the monopoly profit in the remaining periods; thus total profits are $2\left(p^{M}\left(c_{L}\right)-c_{L}\right)(80-$ $\left.p^{M}\left(c_{L}\right)\right)-3 F$. The only conceivable profitable deviation would be to underbid the competitor; which would then also mean $L$ has to set the same price in the future. This would give profits of at most $3\left(\widetilde{p}_{2}-c_{L}\right)\left(80-\widetilde{p}_{2}\right)-3 F$. By construction of $\widetilde{p}_{2}$, firm $L$ is indifferent between these two profits if $p=\widetilde{p}_{2}$ because

$$
3\left(\widetilde{p}_{2}-c_{L}\right)\left(80-\widetilde{p}_{2}\right)=2\left(p^{M}\left(c_{L}\right)-20\right)\left(80-p^{M}\left(c_{L}\right)\right)=1800
$$

For any price equilibrium candidate $p_{2}$ in $\left[c_{H}, \widetilde{p}_{2}\right), 3\left(p_{2}-c_{L}\right)\left(80-p_{2}\right)<$ $3\left(\widetilde{p}_{2}-c_{L}\right)\left(80-\widetilde{p}_{2}\right)$; firm $L$ thus strictly prefers firm $H$ to win.

Given that both firms set the same price and firm $H$ wins the market with 
a positive gross profit, she cannot earn higher short-term profits. By avoiding to undercut, $H$ would earn zero gross profits today. But this would not increase profits in the next period, as it would exit anyway (as any price in $\left[c_{H}, \widetilde{p}_{2}\right]$ is above the break-even price of $L$, who will stay).

Period 1: By setting the monopoly price, $L$ can guarantee itself four times the monopoly profit. Clearly this is optimal.

\section{References}

Blume, A. (2003). Bertrand without fudge. Economics Letters 78(2), 167-168.

Kartik, N. (2011). A note on undominated Bertrand equilibria. Economics Letters $111(2), 125-126$. 


\section{B Instructions}

[Instructions for L'FAIRE, translated from German. The parts that are different in the instructions for BROOKE, EDLIN, and BAUMOL are reported in boxes]

General Instructions: We are pleased to welcome you to this economic study. Please read the following instructions carefully. During this study, you have the opportunity to earn a fair amount of money in addition to the 5 Euros that you receive as an initial endowment for participating. The exact amount depends on your decisions and the decisions of the other participants. You remain anonymous during the entire study.

During the study, we do not speak of Euros but of points. Your entire income will first be calculated in points. The total amount of points you earn will be converted to Euros at the end of the study. The following conversion rate applies:

$$
600 \text { points }=1 \text { Euro }
$$

To start with, you receive 1500 points to cover potential losses. At the end of today's session, you will receive your earnings from the study plus the initial endowment of 5 Euros in cash.

We will explain the exact procedure of the study in the next pages. These instructions are solely for private use, please do not communicate with the other participants during the study. If you have any questions, please contact the supervisors.

The Study: This study is divided into 7 separate rounds. In each round, you are paired with another participant selected at random from those present in the room. In each round, you are assigned one of two roles. Either you are firm A or firm B. If you are assigned the role of firm A, the other participant in your group is assigned the role of firm $B$ and vice-versa. These roles are randomly allotted at the beginning of each round and remain unchanged throughout this round. Each round consists of four periods.

Firms A and B produce a homogenous good and sell this in the same market. In each period that your firm participates in the market, you have to set the price at 
which you want to sell the good. At the beginning of each period, if you currently participate in the market, you can decide to exit the market and, if you currently do not participate in the market you can decide to enter it for this period. If you decide to exit the market, you will not be able to enter it anymore for the entire round.

Firm A and firm B differ in two respects:

1. Firm A produces the good at a lower cost than firm B.

2. Firm A starts off in the market at the beginning of period 1 whereas firm $B$ can enter the market only at the beginning of period 2 .

The procedure in a particular round is as follows (see figure A3).

\section{Period 1:}

(1) Firm A is alone in the market and sets a price (see (iii)).

(2) The profit of firm A is realized. Both firms learn the price, the quantity sold and the profit of firm A (see (iv)).

Period 2 and all subsequent periods until the round ends:

(1) Each firm that participates in the market decides whether to exit the market. Once a firm has exited the market, it cannot enter it anymore in this round. In each period in which firm B has not entered the market previously in this particular round, it decides whether to enter the market (see (i)).

(2) Each firm learns the exit, respectively, entry decision of the other firm (see (ii)).

(3) Each firm that participates in the market sets a price (see (iii)).

(4) Profits are realized. Both firms learn prices, quantities sold and profits (see (iv)). 


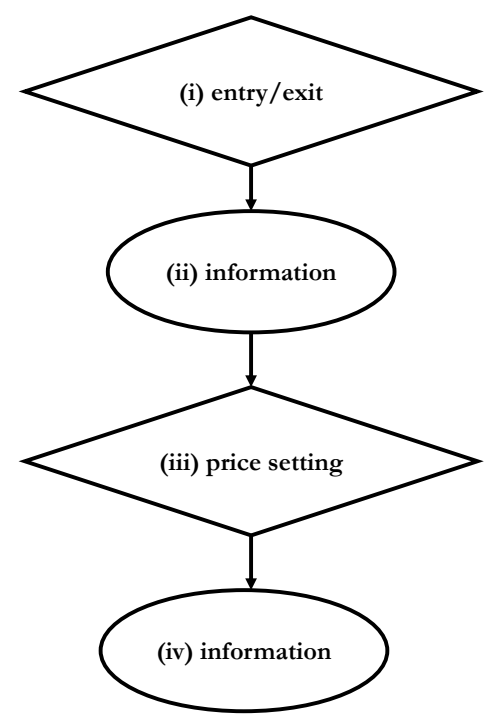

Figure A3: Sequence of Events

The profits are summed up across all periods in each round. After four periods a round ends, and a new round begins. For the new round, participants are newly paired, and the roles of firm A and B are randomly reassigned within these groups. In every round, you are informed only about the decisions of the other firm in your group. When a new round starts and you are matched with a new firm, neither of you will know anything about the decisions of the other firm in prior rounds.

Per-Period Profit: Your profit in each period depends on whether you participate in the market or not:

(i) Each period in which you do not participate in the market, you earn a fixed amount of 50 points with certainty.

(ii) Each period in which you participate in the market, the factors market demand, costs and price setting behavior determines your profit. How these factors determine your profit is explained below.

Market Demand: In each period, each firm that participates in the market has to decide which price to set. Both firms set their price at the same time. However, only the firm with the lower price can sell the good. If the lower price is $P$ the 
firm who sets this price sells $Q$ units of the good. The quantity $Q$ is determined as follows:

$$
Q=80-P
$$

Example: Suppose that you set a price of 70, and you are the firm with the lower price. In this case, you sell 10 units. However, if you are the firm that sets the higher price you do not sell anything. If both of you chose the same price then you both sell half of the quantity $Q$. For example, both set a price of 10 and share the resulting quantity (70) and sell 35 units each.

Costs: Each firm has two kinds of costs:

(i) Each selling firm pays a unit cost of production. This cost is 20 per unit for firm A and 30 per unit for firm B.

Example: Suppose that you are firm A and sell 10 units. Your production cost is then $10 \times 20=200$. If you are firm B and you sell 10 units, your production cost is $10 \times 30=300$.

(ii) For each period in which a firm participates in the market, it has to pay a fixed cost of 250. This cost is the same for firms A and B, and it is independent of production.

Example: Suppose that you participate in the market but do not sell anything. Hence, you make a revenue of zero and pay no unit cost of production. However, you have to pay the fixed cost, and, thus, you make a loss of 250.

Price Setting: Prices are integers in between 0 and 80. You can choose any price in this range. 


\section{Price Setting BRoOKE:}

In certain situations, however, not the entire price range between 0 and 80 is available. The graph below illustrates these situations. The upper part of the graph corresponds to the market situation in an arbitrary period $t$. Three situations are to be distinguished:

- In Situation 1, only you sell the good (black box) in period $t$ while the other firm does not sell anything (white box). The reason why the other firm does not sell anything in period $t$ may be twofold (dashed line):

1. The other firm does not participate in the market in period $t$ or

2. The other firm set a higher price than you did in period $t$.

If now the other firm participates in the market in the next period $t+1$ you are not allowed to set a price in period $t+1$ that is below your own unit cost of production. No restriction applies to the other firm. If the other firm does not participate in the market in period $t+1$ no restriction applies to you.

Example: Suppose that your unit cost of production is 20 and that, currently, only you sell 10 units at a price of 70 . If the other firm participates in the market in the next period, you are not allowed to set a price in the next period that is below 20. The other firm can set any price between 0 and 80 .

- In Situation 2, both you and the other firm set the same price in period $t$ and thus, both sell half of the total quantity each. In the next period $t+1$, neither you nor the other firm are restricted in their price setting.

- In Situation 3, only the other firm sells the good in period $t$. You do not sell anything because, either you do not participate in the market in period $t$ or you set a higher price than the other firm did. If now the other firm participates in the market in the next period $t+1$, it is not allowed to set a price in period $t+1$ that is below its own unit cost of production. If it does not participate in the market, it cannot set any price. In period $t+1$, no restriction applies to you. 


\section{Price Setting BROOKE:}
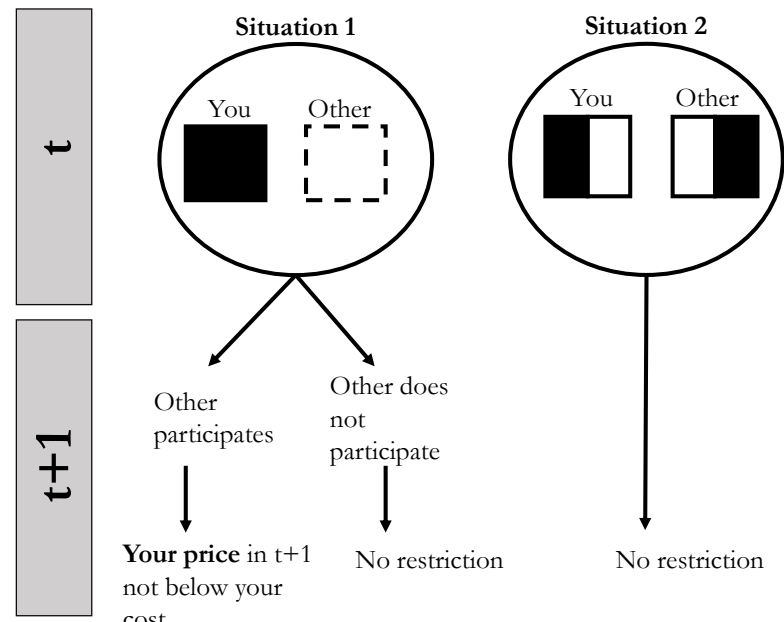

Your price in $\mathrm{t}+$

not below your

cost

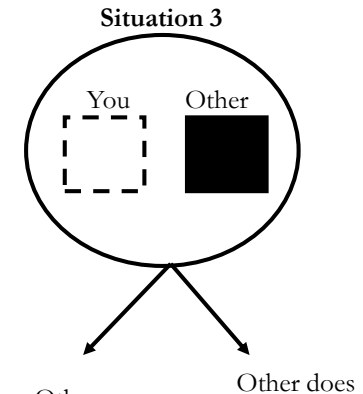

Other

Other does

participates

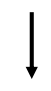

Price Other in $\mathrm{t}+1$ not below Other's

cost

In a nutshell, the following rule applies: the firm that sells the good in $t$, must not set a price in $t+1$ that is below its own unit cost of production if the other firm participates in the market in $t+1$. 


\section{Price Setting EdLIN:}

In certain situations, however, not the entire price range between 0 and 80 is available. The graph below illustrates these situations. The upper part of the graph corresponds to the market situation in an arbitrary period $t$. Three situations are to be distinguished:

- In Situation 1, only you sell the good (black box) in period $t$ while the other firm does not sell anything (white box). The reason why the other firm does not sell anything in period $t$ may be twofold (dashed line):

1. The other firm does not participate in the market in period $t$ or

2. The other firm set a higher price than you did in period $t$.

If now the other firm participates in the market in the next period $t+1$ you are not allowed to set a price in period $t+1$ that is below $80 \%$ of your price in period $t$ (rounded to integers). No restriction applies to the other firm.

Example: Suppose that, currently, only you sell 10 units at a price of 70. If the other firm participates in the market in the next period, you are not allowed to set a price in the next period that is below 56 $(=0.8 \times 70)$ (see supplementary sheet). The other firm can set any price between 0 and 80 .

- In Situation 2, both you and the other firm set the same price in period $t$ and thus, both sell half of the total quantity each. In the next period $t+1$, neither you nor the other firm are restricted in their price setting.

- In Situation 3, only the other firm sells the good in period $t$. You do not sell anything because, either you do not participate in the market in period $t$ or you set a higher price than the other firm did. If now the other firm participates in the market in the next period $t+1$, it is not allowed to set a price in period $t+1$ that is below $80 \%$ of its price in period $t$. In period $t+1$, no restriction applies to you. 


\section{Price Setting EDLIN:}
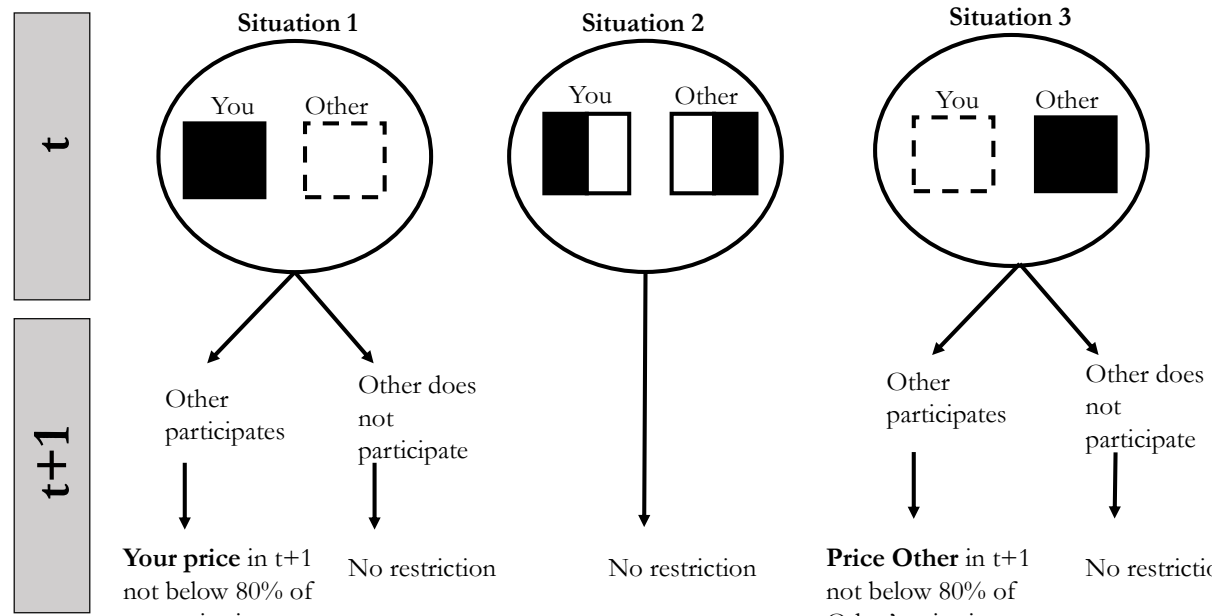

Other participates not

$\downarrow$ participate participates

participate

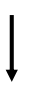

No restriction

Your price in $\mathrm{t}+1$

not below $80 \%$ of

No restriction your price in $\mathrm{t}$

Price Other in $\mathrm{t}+1 \quad$ No restriction

not below $80 \%$ of Other's price in $t$

In a nutshell, the following rule applies: the firm that sells the good in $t$, must not set a price in $t+1$ that is below $80 \%$ of its price in $t$ (rounded to integers) if the other firm participates in the market in $t+1$. 


\section{Price Setting BAumoL:}

In certain situations, however, not the entire price range between 0 and 80 is available. The graph below illustrates these situations. The upper part of the graph corresponds to the market situation in an arbitrary period $t$. Three situations are to be distinguished:

- In Situation 1, both you and the other firm participate in the market but only you sell the good in period $t$; the other firm sells nothing. If now the other firm exits the market and thus does not participate in the market in the next period $t+1$, you are not allowed to increase your price in $t+1$ and in all subsequent periods in this round. If the other firm participates in the market in the next period $t+1$ no restriction applies to you or the other firm.

Example: Suppose that, currently, both participate in the market, but that you are the one who set the lower price, say, 70. In the current period, only you sell the good, namely, 10 units. If the other firm exits the market in the next period you are not allowed to increase your price above 70 in the next and all subsequent periods in this round.

- In Situation 2, both you and the other firm set the same price in period $t$ and thus, both sell half of the total quantity each. In the next period $t+1$, neither you nor the other firm are restricted in their price setting.

- In Situation 3, both you and the other firm participate in the market but only the other firm sells the good in period $t$; you sell nothing. If now you exit the market and thus do not participate in the market in the next period $t+1$, the other firm is not allowed to increase its price in $t+1$ and in all subsequent periods in this round. If you participate in the market in the next period $t+1$ no restriction applies to you or the other firm. 


\section{Price Setting BAUMOL}
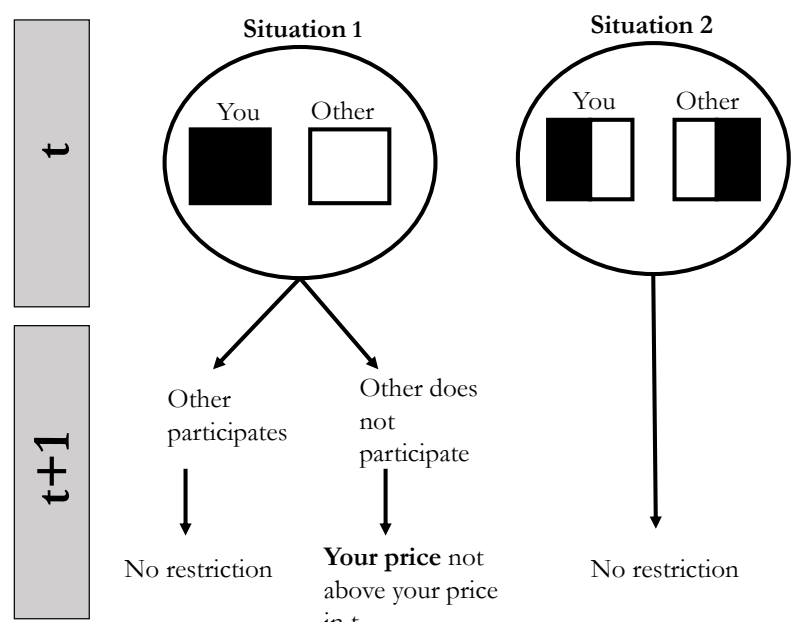

No restriction participates

Other does

not

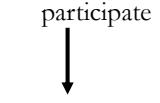

Your price not above your price in $\mathrm{t}$

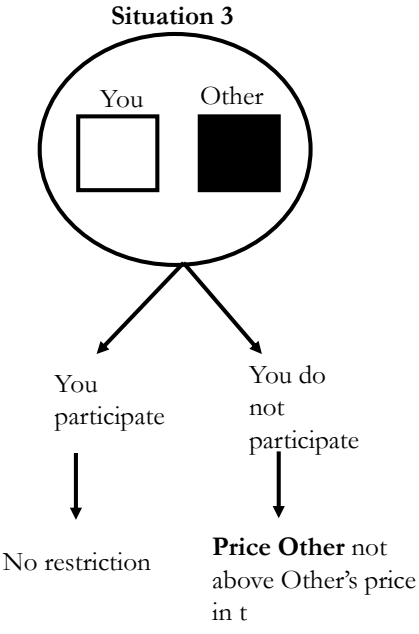

In a nutshell, the following rule applies: the firm that sells the good in $t$, must not increase its price in $t+1$ and until the end of this round if the other firm exits the market in $t+1$.

Calculation of Per-Period Profit: The per-period profit is calculated as follows: each firm makes a revenue which equals price times units sold $(P \times Q)$. Subtracting the total cost incurred, that is, the sum of the production cost and the fixed cost, gives the per-period profit.

Example: Suppose that you currently sell 10 units at a price of 70 . With the cost of firm A, the profit yield is $70 \times 10-10 \times 20-250$, that is, 250 . With the cost of firm $\mathrm{B}$, the profit yield is $70 \times 10-10 \times 30-250$, that is, 150 . 
Procedure: In each period, each firm that participates in the market sees the input screen. In period 1, this screen appears only for firm A. Firm A thus sees the following input screen:

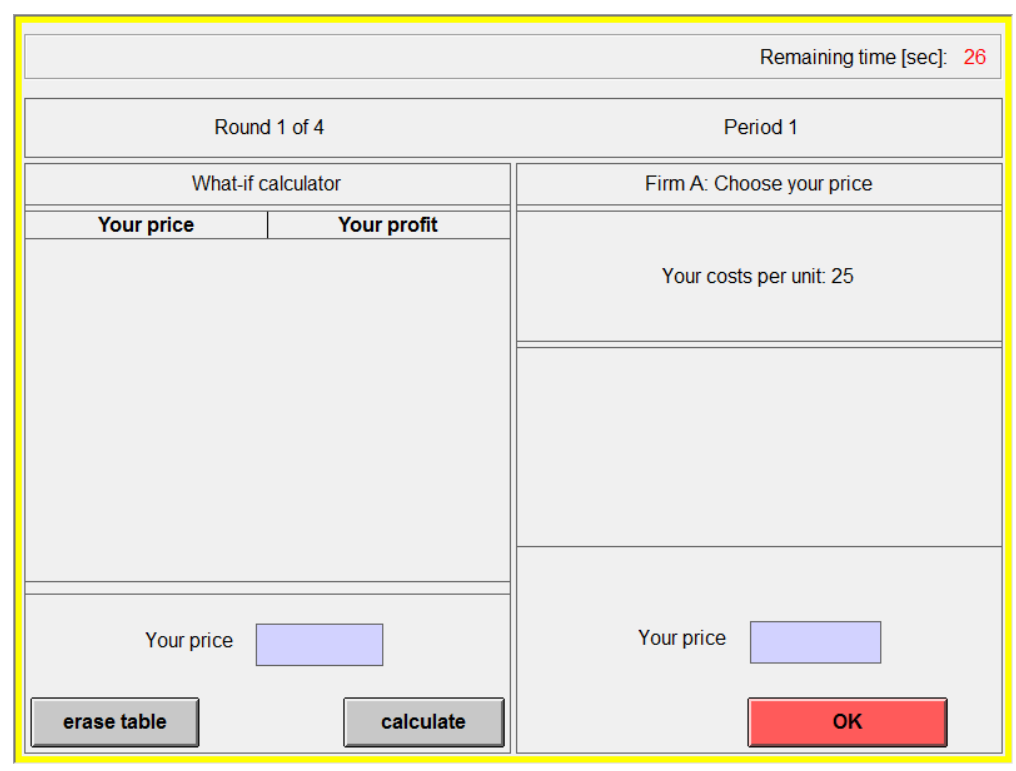

The upper part of the screen shows the round in which you are in on the left; in this example, it is round 1 of 7 . On the right, you see a time specification in seconds which indicates how much time you have left to enter your price. Please try to reach your decision in the given time. Below the time indication, you see in which period you are in. In this example, it is period 1. The remaining part of the screen is divided into two sections. On the left, you can see the "What-if-calculator". You can use this tool to determine your per-period profit using different prices. On the right, the screen reminds you of your unit cost of production; in this example, 20 is shown as a value. Below the cost information, you can enter the price you want to set in this period. In order to confirm a price, you must click on the "OK" button. You can revise your price until you click on this button. Once you have done this, you can no longer revise your decision for this period. 
Notice that the layout of this screen as well as the "What-if-calculator" adapts to the situation, namely, whether only one or both firms are in the market. In particular, when both firms participate in the market, the input screen appears as follows:

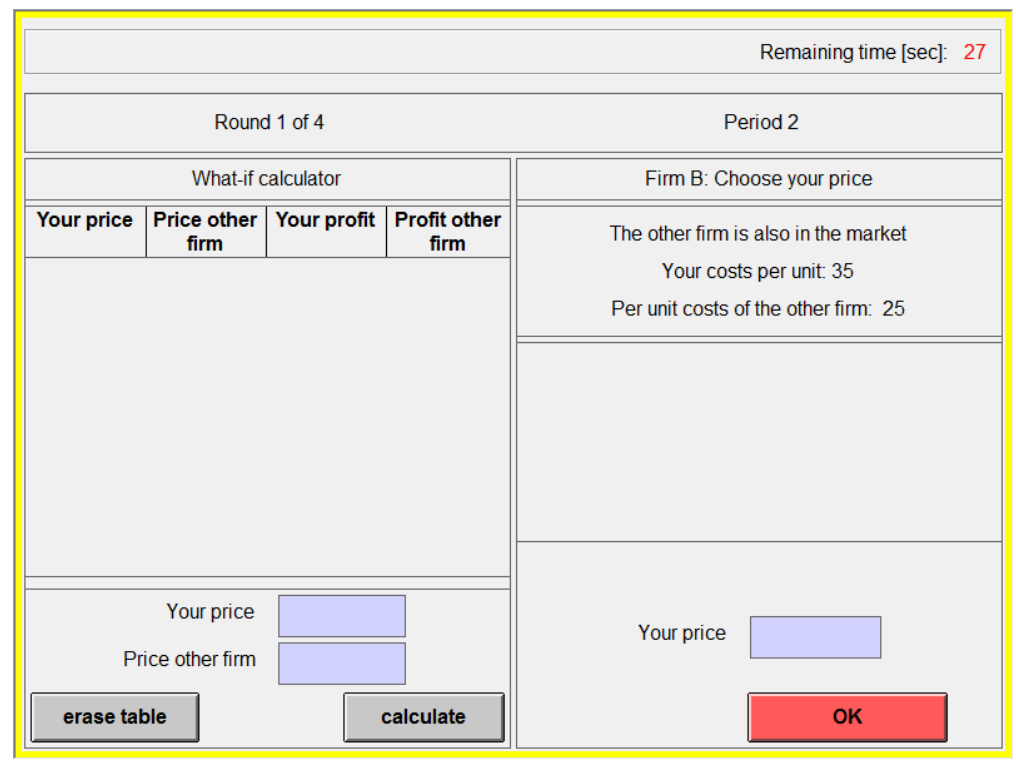

Here, in the example, you see the input screen of firm B in period 2 of round 1. The left part of the screen shows again the "What-if-calculator". Now you can calculate your profit as a combination of your price and the price of the other firm. On the right, you can see, in addition to your unit production cost, the unit production cost of the other firm as well as whether this firm participates in the market.

\section{Brooke, EdLin, BaUmol}

If either your or the other firm's price range is restricted, it is always indicated on this input screen below the cost information. If none of the price ranges is restricted in any way, nothing is indicated. In this example, neither your not the other firm's price range is restricted: You can both set any price between 0 and 80 . 
In each period (other than period 1) in which firm B has not entered the market previously in this particular round, firm B has to decide whether to enter the market for this period. Only if firm B enters the market, it can set a price. Below the cost information, the screen reminds firm B of the price that firm A set in the previous period.

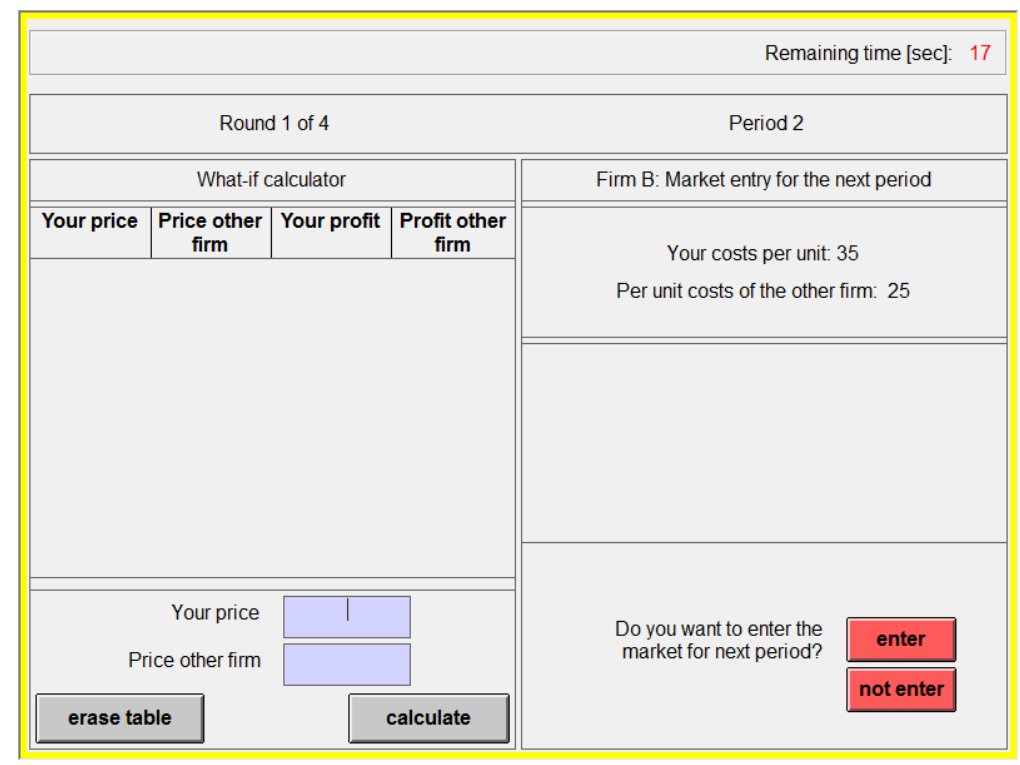

Each firm learns the exit, respectively, entry decision of the other firm. Each firm that participates in the market in this period then goes on to price setting via the input screen as it is explained above. Each firm that does not participate in the market in this period can set no price and will be informed on the price, quantity sold and potential profits at the end of this period.

Do you have any further questions? If so, please raise your hand. The supervisors will come to you at your workplace. Otherwise, we kindly ask you to answer the control questions on your screen. 